\title{
sciendo
}

Int. J. of Applied Mechanics and Engineering, 2018, vol.23, No.4, pp.941-961

DOI: $10.2478 /$ ijame-2018-0053

\section{STUDY ON HARMONIC ANALYSIS OF FUNCTIONALLY GRADED PLATES USING FEM}

\author{
A.K. SHARMA* \\ Rajkiya Engineering College \\ Mainpuri, INDIA - 205119 \\ E-mail: avadesh_sharma@rediffmail.com \\ P. SHARMA \\ Madhav Institute of Technology and Science \\ Gwalior, INDIA \\ P.S. CHAUHAN \\ IPS- College of Technology and Management \\ Gwalior, INDIA \\ S.S. BHADORIA \\ Dr. B.R. Ambedkar National Institute of Technology \\ Jalandhar, INDIA
}

\begin{abstract}
This paper presents the harmonic and vibration analysis of functionally graded plates using the finite element method. Initially, the plates are assumed isotropic and the material properties of it are assumed to vary continuously through their thickness direction according to a power-law distribution of the volume fractions of the plate constituents. The four noded shell element is used to analyse the functionally graded plates. Four functionally graded plates- $\mathrm{Al} / \mathrm{Al}_{2} \mathrm{O}_{3}, \mathrm{Al} / \mathrm{ZrO}{ }_{2}, \mathrm{Ti}-6 \mathrm{Al}-4 \mathrm{~V} /$ Aluminium oxide, and $\mathrm{SUS} 304 / \mathrm{Si}_{3} \mathrm{~N}_{4}$ are considered in the study, and their results are obtained so that the right choice can be made in applications in high temperature environment and in reducing the vibration amplitudes in applications such as aircrafts, rockets, missiles, etc. Numerical results for the natural frequency and harmonic response amplitude are presented. Results are compared and validated with available results in the literature. Effects of boundary conditions, material and damping on natural frequency and harmonic response of the functionally graded plates are also investigated.
\end{abstract}

Key words: finite element method, functionally graded plate, free vibration.

\section{Introduction}

Functionally graded materials (FGMs) are special composites with material properties that vary continuously through their thickness resulting in corresponding changes in the properties of the material. FGMs are usually made of a mixture of ceramic and metal, and can thus resist high-temperature conditions while maintaining toughness. The concept of functionally graded materials (FGMs) was first introduced in 1984 by a group of material scientists in Japan, as ultrahigh temperature resistant materials for aircraft, space vehicles and other engineering applications [1-2]. Functionally graded material (FGM) may be characterized by the variation in composition and structure gradually over volume, resulting in corresponding changes in the properties of the material. The materials can be designed for specific function and applications. Various approaches based on the bulk (particulate processing), layer processing and melt processing are used to

\footnotetext{
* To whom correspondence should be addressed
} 
fabricate the functionally graded materials [3]. There are many areas of application for FGMs. The concept is to make a composite material by varying the microstructure from one material to another material with a specific gradient. This enables the material to have the best of both materials. If it is for thermal, or corrosive resistance or malleability and toughness both strengths of the material may be used to avoid corrosion, fatigue, fracture and stress corrosion cracking [4]. The transition between the two materials can usually be approximated by means of a power series. The aircraft and aerospace industry and the computer circuit industry are very interested in the possibility of having materials that can withstand very high thermal gradients. This is normally achieved by using a ceramic layer connected with a metallic layer [5-6]. The dynamic behaviour of each element is derived and the solution of the structure as a whole is reconstituted by attaching each element together at its node points. Predicting the dynamic response of a vibrating system generally involves determining the equations of motion of the structure and solving them for given boundary conditions [7]. Finite element methods are one of the most widely used deterministic techniques. For this technique, a structure is divided into a number of elements. These methods are extensively used to predict the linear dynamic response of structures in the low frequency region. For more complex systems, the equations of motion can be approximated using various deterministic modelling techniques such as the finite element analysis [8]. In engineering design, it is important to calculate the response quantities such as the displacement, stress, vibration frequencies, and mode shapes of a given set of design parameters [9]. The natural frequencies and mode shapes can then be used to predict the response due to an applied excitation. The vibration and harmonic responses of composite plates and FGMs have been extensively studied by a number of researchers [12-16]. However, the aim of the work is to study the effect of functionally graded materials on the vibration behavior by making a modal and harmonic analysis of the models.

\section{Functionally graded material properties}

A functionally graded plate (shown in Fig.1) is considered to be a single-layered plate of uniform thickness that is made of ceramic and metal. The material property is assumed to be graded through the thickness in accordance with a power-law distribution that is expressed as

$$
\begin{aligned}
& P(z)=\left(P_{c}-P_{m}\right) V_{c}+P_{m}, \\
& V_{c}=(1 / 2+z / h)^{n}, \quad(n \geq 0)
\end{aligned}
$$

where, $P$ represents the effective material property, $P_{c}$ and $P_{m}$ denote the properties of the ceramic and metal, respectively, $V_{c}$ is the volume fraction of the ceramic, $h$ is the thickness of the plate, and $n$ is the volume fraction exponent. Figure 2 shows the variation of the volume fraction through the thickness for different exponent $n$.

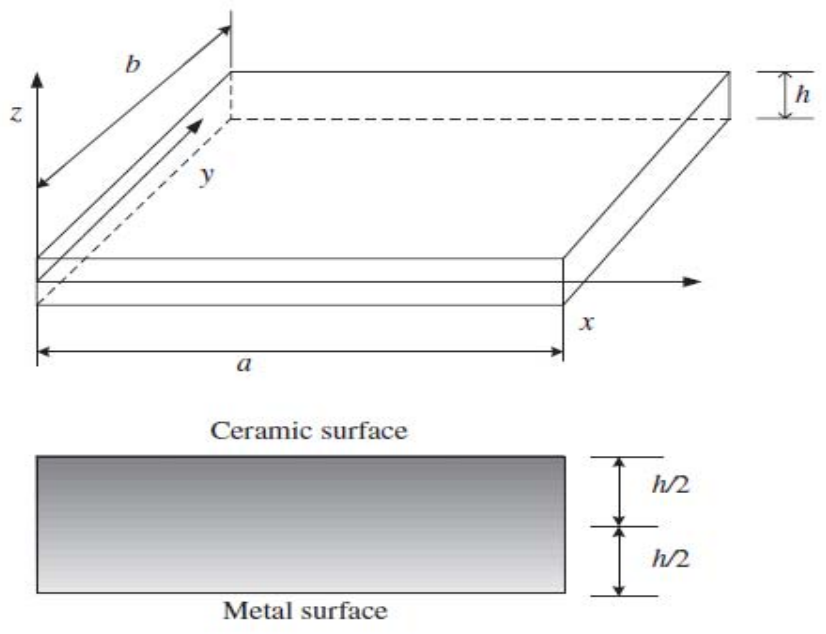

Fig.1. Functionally graded plate. 


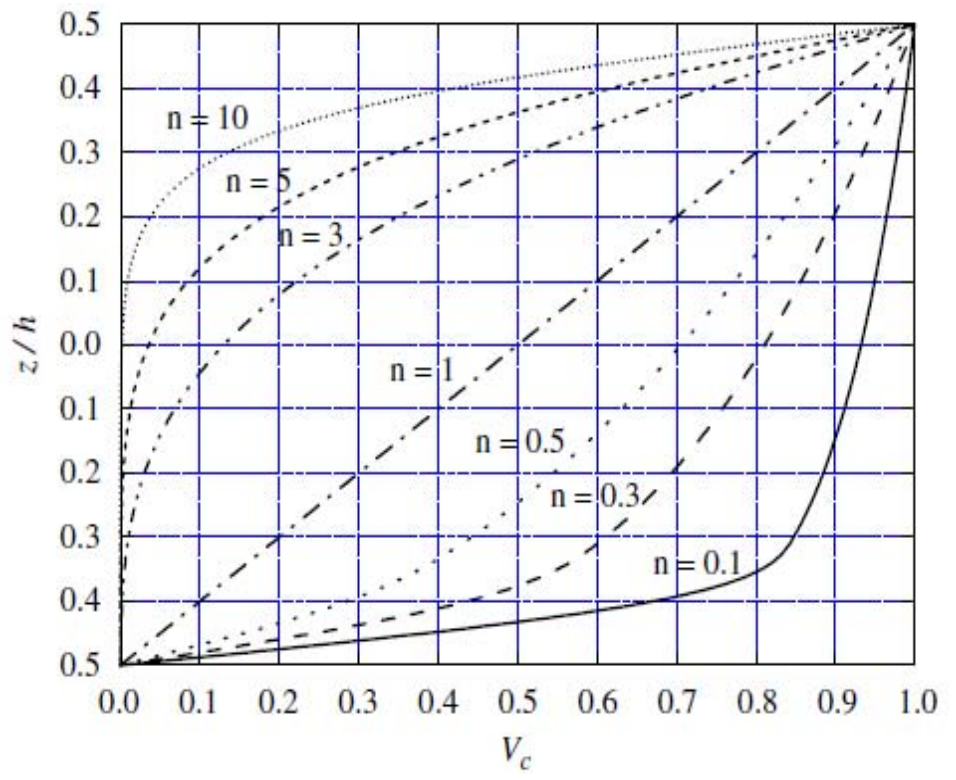

Fig.2. Variation of volume fraction $V_{c}$ through the thickness.

\section{Methodology}

\subsection{Background}

ANSYS 15.0 with mechanical APDL is used to analyse the functionally graded plate. The analysis was done on moderately thick square FG plates with various combinations of simply supported and clamped boundary conditions. It consisted of building geometry of the model and distributing the FGM material properties along the thickness of the model, meshing the model with a proper smart sized mesh types, applying loads on the model, setting boundary conditions on the model, and finally running and solving the model. Modal analysis is done to find the system vibration parameters (i.e., natural frequencies, and mode shapes). And then for all these combinations harmonic analysis is done to find out the frequency response of plate.

\subsection{Modelling}

According to the material properties shown in Tab.1 and using ANSYS 15.0 with mechanical APDL capabilities, a harmonic analysis problem has been solved for FGM models. A square FG plate of $304.8 \mathrm{~mm}$ x $304.8 \mathrm{~mm} \times 2 \mathrm{~mm}$ is considered in the study which is subjected to a force of $1 \mathrm{~N}$ at the node location $(75$ $\mathrm{mm}, 152.4 \mathrm{~mm}$ ), as shown in Fig.4. The element SHELL181 was chosen to mesh the model. It is a four-node element with six degrees of freedom at each node: three translations in the $x, y$, and $z$ directions, and three rotations about the $x, y$, and $z$-axis. It is suitable for analyzing thin to moderately-thick shell structures and can be used for layered applications for modelling composites. The degenerate triangular option should only be used as filler elements in mesh generation. This makes the comparison between the different FG models easy. 


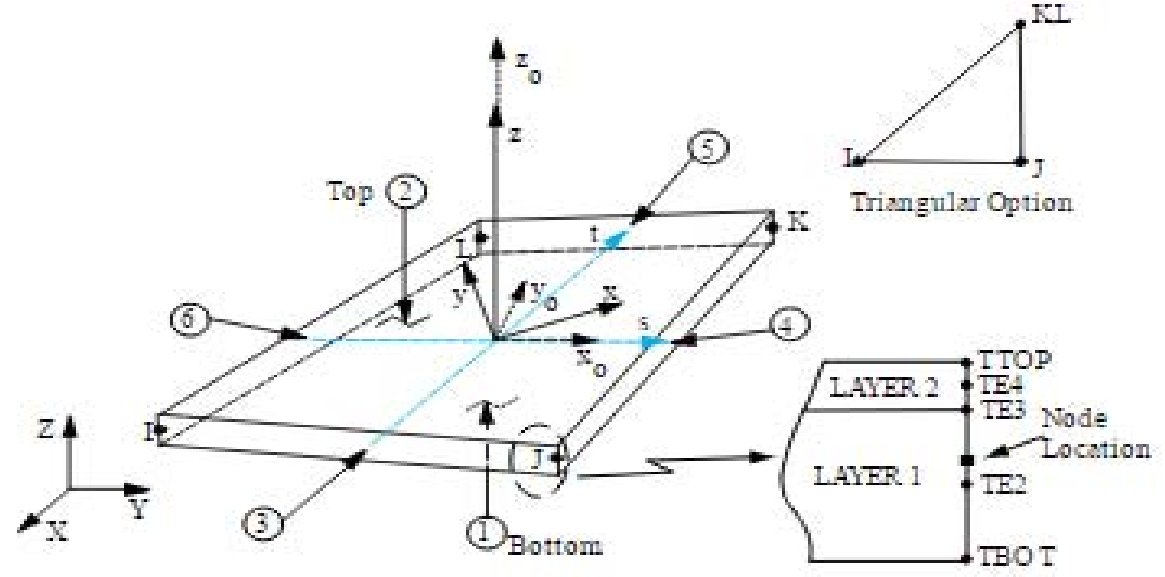

Fig.3. SHELL181 Geometry.

In this section, the frequency characteristics of four types of square plates- $\mathrm{Al} / \mathrm{Al} 2 \mathrm{O} 3, \mathrm{Al} / \mathrm{ZrO} 2, \mathrm{Ti}-$ 6Al-4V/ Aluminium oxide, and SUS304/Si3N4- are investigated. The properties of the constituents are provided in Tab.1. The volume fraction exponent $n$ is taken as 1 . Two types of boundary conditions - all edges clamped (CCCC) and all edges simply supported (SSSS) are considered.

The simply supported boundary condition is expressed as

At

$$
x=0, \text { a: } v_{0}=w_{0}=\theta_{y}=0 .
$$

At

$$
y=-b / 2, b / 2: u_{0}=w_{0}=\theta_{x}=0 .
$$

The boundary conditions at the clamped edges are given by

$$
u_{0}=v_{0}=w_{0}=\theta_{x}=\theta_{y}=0 .
$$

Figures $4 \mathrm{a}$ and $4 \mathrm{~b}$ shows the geometry and loads for the FG plate at the SSSS and CCCC boundary condition respectively.

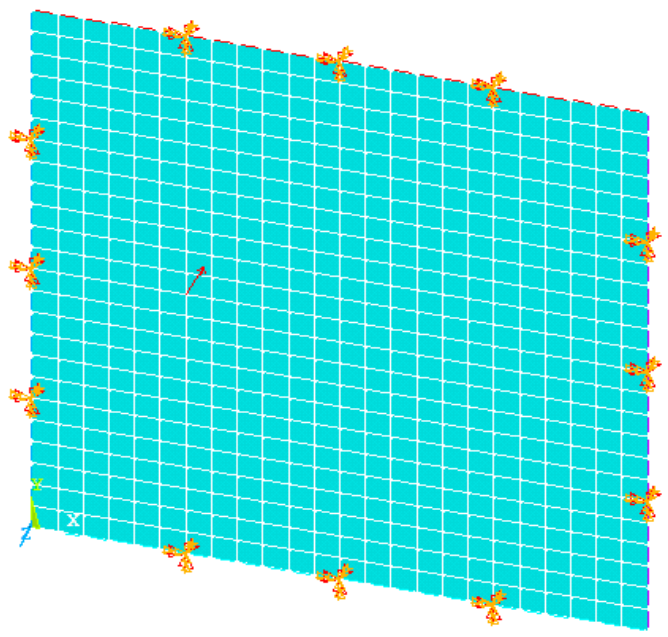

Fig.4a.

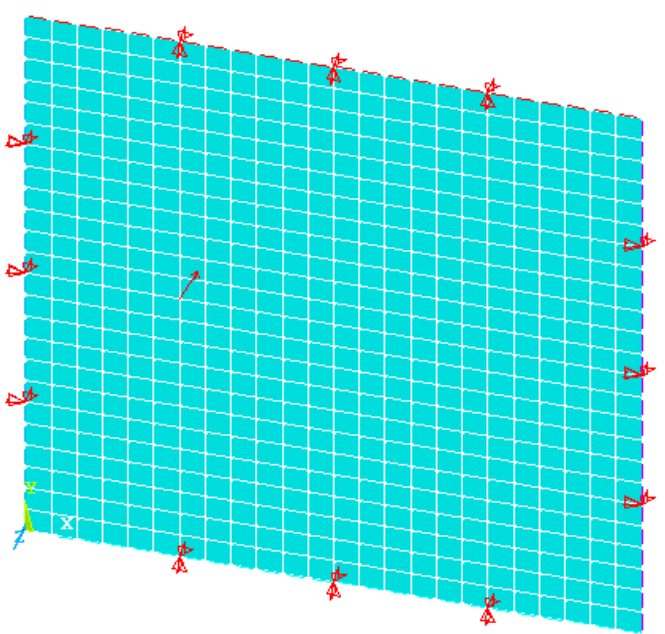

Fig.4b. 
Modal Analysis is done to compute the first 10 natural frequencies for each model. The solver used for modal analysis is Block Lanczos. For the plates with the CCCC and SSSS boundary condition, the frequency decreases, as the volume fraction exponent $n$ increases. This is expected because a larger volume fraction exponent means that the plate has a smaller ceramic component, and that its stiffness is thus reduced. The last one is Harmonic Analysis, and the results were a comparison between the frequency response amplitude values in each model, and this will be discussed in the following section.

Table 1. Material properties of FGM materials.

\begin{tabular}{lccc}
\hline Material & Elasticity modulus $(\mathrm{GPa})$ & Poisson's ratio & Density \\
\hline Aluminium $(\mathrm{Al})$ & 70 & 0.3 & 2707 \\
Alumina $\left(\mathrm{Al}_{2} \mathrm{O}_{3}\right)$ & 380 & 0.3 & 3800 \\
Ti-6Al-4V & 105.7 & 0.298 & 4429 \\
Aluminium oxide & 320.2 & 0.26 & 3750 \\
Zirconia $\left(\mathrm{ZnO}_{2}\right)$ & 151 & 0.3 & 3000 \\
Stainless steel SUS304 & 207.78 & 0.3177 & 8166 \\
Silicon nitride & 322.27 & 0.24 & 2370 \\
\hline
\end{tabular}

\section{Results}

\subsubsection{Modal analysis}

The variation of the frequency parameter with the boundary condition and with the volume fraction exponent for plates made of $\mathrm{Al} / \mathrm{Al}_{2} \mathrm{O}_{3}, \mathrm{Al} / \mathrm{ZrO}_{2}, \mathrm{Ti}-6 \mathrm{Al}-4 \mathrm{~V} / \mathrm{Aluminium}$ oxide andSUS304/Si $\mathrm{N}_{4}$, is described in Tabs 2-5, respectively. They show a comparison of the fundamental natural frequency parameters of the four plates. It can be seen that all of the frequencies that represent the various combinations show a similar behaviour, with the frequencies dropping as the volume fraction exponent increases.

Table 2. Variation of the frequency parameter with the volume fraction exponent $n$ for the square $\mathrm{Al}_{1} / \mathrm{Al}_{2} \mathrm{O}_{3}$ FG plate.

\begin{tabular}{|l|l|l|l|l|l|l|l|l|l|l|l|}
\hline B.C. & \multicolumn{10}{|l|}{$M O D E$} & $\mathbf{6}$ \\
\hline & $\boldsymbol{n}$ & $\mathbf{1}$ & $\mathbf{2}$ & $\mathbf{3}$ & $\mathbf{4}$ & $\mathbf{5}$ & $\mathbf{6}$ & $\mathbf{7}$ & $\mathbf{8}$ & $\mathbf{9}$ & $\mathbf{1 0}$ \\
\hline & & & & & & & & & & & \\
\hline CCCC & $n=0$ & 374.3 & 768.64 & 768.64 & 1132.1 & 1395.6 & 1402.5 & 1739.8 & 1739.8 & 2271.8 & 2271.8 \\
\hline & $n=1$ & 311.3 & 639.2 & 639.2 & 941.4 & 1160.5 & 1166.1 & 1446.8 & 1446.8 & 1889.3 & 1889.3 \\
\hline & $n=10$ & 254.2 & 522.0 & 522.0 & 768.9 & 947.9 & 952.4 & 1181.7 & 1181.7 & 1543.1 & 1543.1 \\
\hline & & & & & & & & & & & \\
\hline SSSS & $n=0$ & 204.8 & 514.5 & 514.5 & 822.9 & 1039.5 & 1039.5 & 1345.7 & 1345.7 & 1792.9 & 1792.9 \\
\hline & $n=1$ & 170.3 & 427.9 & 427.9 & 684.34 & 864.4 & 864.4 & 1119.1 & 1119.1 & 1491.0 & 1491.0 \\
\hline & $n=10$ & 139.1 & 349.5 & 349.5 & 558.9 & 706.0 & 706.0 & 914.0 & 914.0 & 1217.8 & 1217.8 \\
\hline
\end{tabular}


Table 3. Variation of the frequency parameter with the volume fraction exponent $n$ for the square Ti-6Al4V/Aluminium oxide FG plate.

\begin{tabular}{|l|l|l|l|l|l|l|l|l|l|l|l|}
\hline B.C. & \multicolumn{1}{l|}{$M O D E$} & \multicolumn{10}{l|}{} \\
\hline & $\boldsymbol{n}$ & $\mathbf{1}$ & $\mathbf{2}$ & $\mathbf{3}$ & $\mathbf{4}$ & $\mathbf{5}$ & $\mathbf{6}$ & $\mathbf{7}$ & $\mathbf{8}$ & $\mathbf{9}$ & $\mathbf{1 0}$ \\
\hline & & & & & & & & & & & \\
\hline CCCC & $n=0$ & 341.7 & 701.7 & 701.7 & 1033.6 & 1274.1 & 1280.2 & 1588.5 & 1588.5 & 2074.2 & 2074.2 \\
\hline & $n=1$ & 268.3 & 551.0 & 551.0 & 811.6 & 1000.4 & 1005.3 & 1247.3 & 1247.3 & 1628.6 & 1628.6 \\
\hline & $n=10$ & 221.5 & 454.8 & 454.8 & 670.0 & 825.9 & 829.8 & 1029.6 & 1029.6 & 1344.5 & 1344.5 \\
\hline & & & & & & & & & & & \\
\hline SSSS & $n=0$ & 187.0 & 469.7 & 469.7 & 751.2 & 948.9 & 948.9 & 1228.5 & 1228.5 & 1636.8 & 1636.8 \\
\hline & $n=1$ & 146.8 & 368.8 & 368.8 & 589.9 & 745.1 & 745.1 & 964.6 & 964.6 & 1285.3 & 1285.3 \\
\hline & $n=10$ & 121.23 & 304.52 & 304.52 & 487.0 & 615.1 & 615.1 & 796.3 & 796.3 & 1061.1 & 1061.1 \\
\hline
\end{tabular}

Table 4. Variation of the frequency parameter with the volume fraction exponent $n$ for the square $\mathrm{Al} / \mathrm{ZrO}_{2} \mathrm{FG}$ plate.

\begin{tabular}{|l|l|l|l|l|l|l|l|l|l|l|l|}
\hline B.C. & \multicolumn{1}{|l|}{$M O D E$} & $\mathbf{6}$ & $\mathbf{6}$ & $\mathbf{6}$ \\
\hline & $\boldsymbol{n}$ & $\mathbf{1}$ & $\mathbf{2}$ & $\mathbf{3}$ & $\mathbf{4}$ & $\mathbf{5}$ & $\mathbf{6}$ & $\mathbf{7}$ & $\mathbf{8}$ & $\mathbf{9}$ & $\mathbf{1 0}$ \\
\hline & & & & & & & & & & & \\
\hline CCCC & $n=0$ & 265.5 & 545.3 & 545.3 & 803.1 & 990.0 & 994.8 & 1234.3 & 1234.3 & 1611.8 & 1611.8 \\
\hline & $n=1$ & 232.9 & 478.3 & 478.3 & 704.5 & 868.4 & 872.6 & 1082.7 & 1082.7 & 1413.7 & 1413.7 \\
\hline & $n=10$ & 209.9 & 431.1 & 431.1 & 635.0 & 782.8 & 786.6 & 975.9 & 975.9 & 1274.4 & 1274.4 \\
\hline & & & & & & & & & & & \\
\hline SSSS & $n=0$ & 145.3 & 365.0 & 365.0 & 583.8 & 737.4 & 737.4 & 954.6 & 954.6 & 1272.0 & 1272.0 \\
\hline & $n=1$ & 127.4 & 320.2 & 320.2 & 512.0 & 646.8 & 646.8 & 837.3 & 837.3 & 1115.7 & 1115.7 \\
\hline & $n=10$ & 114.9 & 288.6 & 288.6 & 461.6 & 583.0 & 583.0 & 754.8 & 754.8 & 1005.7 & 1005.7 \\
\hline
\end{tabular}

Table 5. Variation of the frequency parameter with the volume fraction exponent $n$ for the square $\mathrm{SUS} 304 / \mathrm{Si}_{3} \mathrm{~N}_{4} \mathrm{FG}$ plate.

\begin{tabular}{|l|l|l|l|l|l|l|l|l|l|l|l|}
\hline B.C. & \multicolumn{1}{l|}{$M O D E$} & $\mathbf{6}$ & $\mathbf{6}$ \\
\hline & $\boldsymbol{n}$ & $\mathbf{1}$ & $\mathbf{2}$ & $\mathbf{3}$ & $\mathbf{4}$ & $\mathbf{5}$ & $\mathbf{6}$ & $\mathbf{7}$ & $\mathbf{8}$ & $\mathbf{9}$ & $\mathbf{1 0}$ \\
\hline & & & & & & & & & & & \\
\hline CCCC & $n=0$ & 429.0 & 880.8 & 880.8 & 1297.5 & 1599.4 & 1607.1 & 1994.1 & 1994.1 & 2603.7 & 2603.7 \\
\hline & $n=1$ & 263.7 & 541.5 & 541.5 & 797.6 & 983.3 & 988.0 & 1225.9 & 1225.9 & 1600.7 & 1600.7 \\
\hline & $n=10$ & 216.5 & 444.5 & 444.5 & 654.8 & 807.1 & 811.0 & 1006.3 & 1006.3 & 1314.0 & 1314.0 \\
\hline & & & & & & & & & & & \\
\hline SSSS & $n=0$ & 234.7 & 589.6 & 589.6 & 943.0 & 1191.2 & 1191.2 & 1542.1 & 1542.1 & 2054.7 & 2054.7 \\
\hline & $n=1$ & 144.33 & 362.5 & 362.5 & 579.8 & 732.4 & 732.4 & 948.1 & 948.1 & 1263.3 & 1263.3 \\
\hline & $n=10$ & 118.4 & 297.6 & 297.6 & 475.9 & 601.2 & 601.2 & 778.3 & 778.3 & 1037.0 & 1037.0 \\
\hline
\end{tabular}

Verification of modal analysis

Table 6 shows the variation of the non dimensional frequency parameter with the volume fraction exponent for the $\mathrm{Al} / \mathrm{Al}_{2} \mathrm{O}_{3}$ plates $(a / h=10)$. Only the results for the first four modes are computed. The 
results as listed in the table, show that the natural frequencies are in good agreement with the results of other authors.

Table 6. Variation of the frequency parameter with the volume fraction exponent $n$ for the square $\mathrm{Al} / \mathrm{Al}_{2} \mathrm{O}_{3}$ FG plate.

\begin{tabular}{|c|c|c|c|c|c|}
\hline \multicolumn{2}{|l|}{ B.C. } & \multicolumn{4}{|l|}{$M O D E$} \\
\hline & $n$ & 1 & 2 & 3 & 4 \\
\hline \multirow[t]{3}{*}{$\mathrm{CCCC}$} & $n=0$, Present & 9.85 & 18.81 & 18.81 & 26.36 \\
\hline & $n=0$, Zhao $[10]$ & 9.63 & 18.31 & 18.31 & 25.49 \\
\hline & Error & $2.28 \%$ & $2.73 \%$ & $2.73 \%$ & $4.05 \%$ \\
\hline \multirow[t]{3}{*}{ SSSS } & $n=0$, Present & 5.54 & 13.46 & 13.46 & 20.44 \\
\hline & $n=0$, Zhao $[10]$ & 5.67 & 13.53 & 13.53 & 20.63 \\
\hline & Error & $2.29 \%$ & $0.51 \%$ & $0.51 \%$ & $0.92 \%$ \\
\hline
\end{tabular}

Results of modal analysis show that the natural frequencies for the plates $\mathrm{Ti}-6 \mathrm{Al}-4 \mathrm{~V} / \mathrm{Aluminium}$ oxide, and SUS304/Si ${ }_{3} \mathrm{~N}_{4}$ nearly overlap, whereas the plate $\mathrm{Al} / \mathrm{Al}_{2} \mathrm{O}_{3}$ has the highest values and the plate $\mathrm{Al} / \mathrm{ZrO}_{2}$ has lowest. A comparison of the 10 natural frequencies of the $\mathrm{FG}$ models with $\mathrm{CCCC}$ boundary condition is shown in Fig.5.

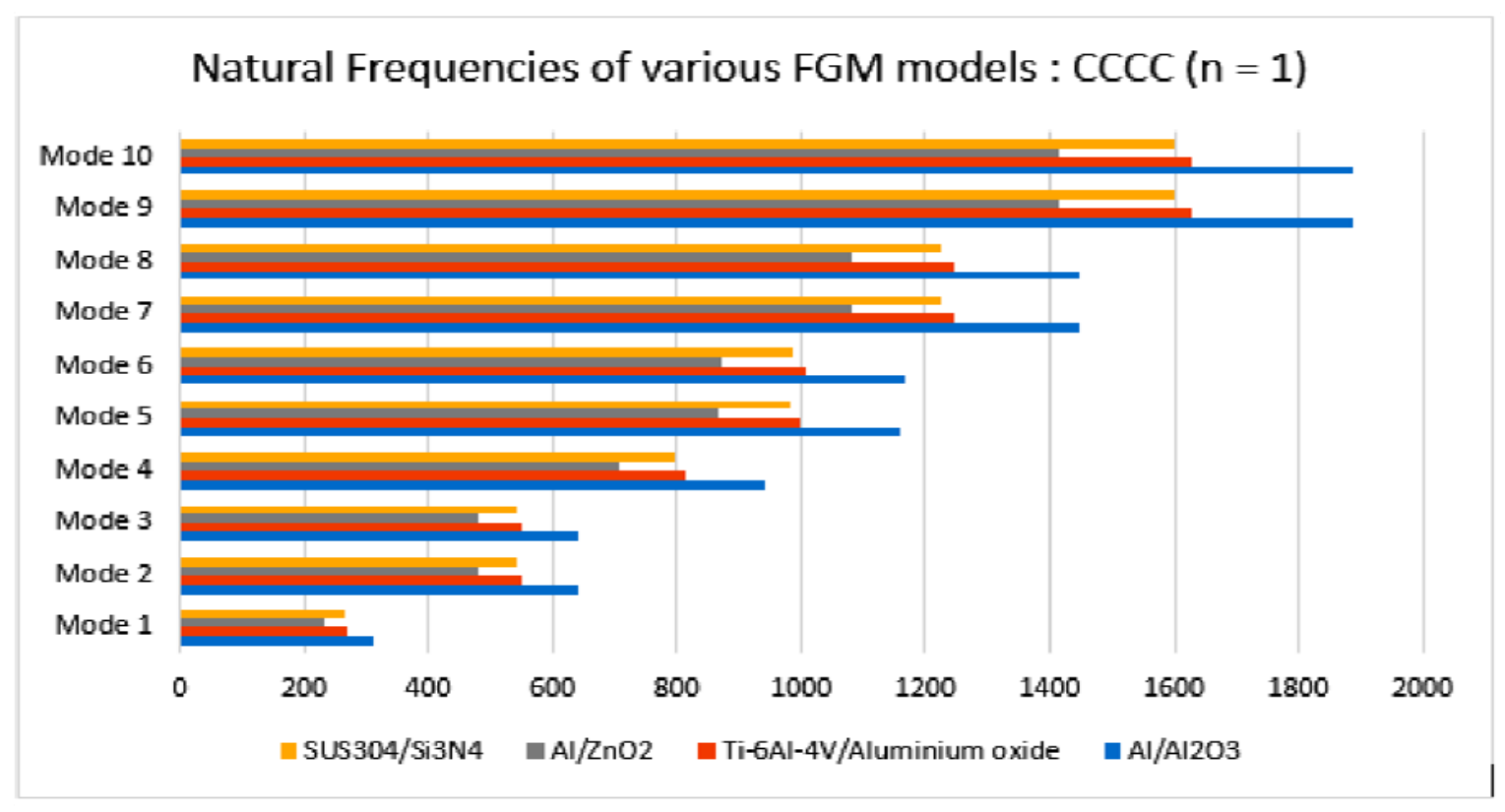

Fig.5. Natural frequencies of the FG plate with CCCC boundary condition.

A comparison of the 10 natural frequencies of the FG models with SSSS boundary condition is shown in Fig.6. 


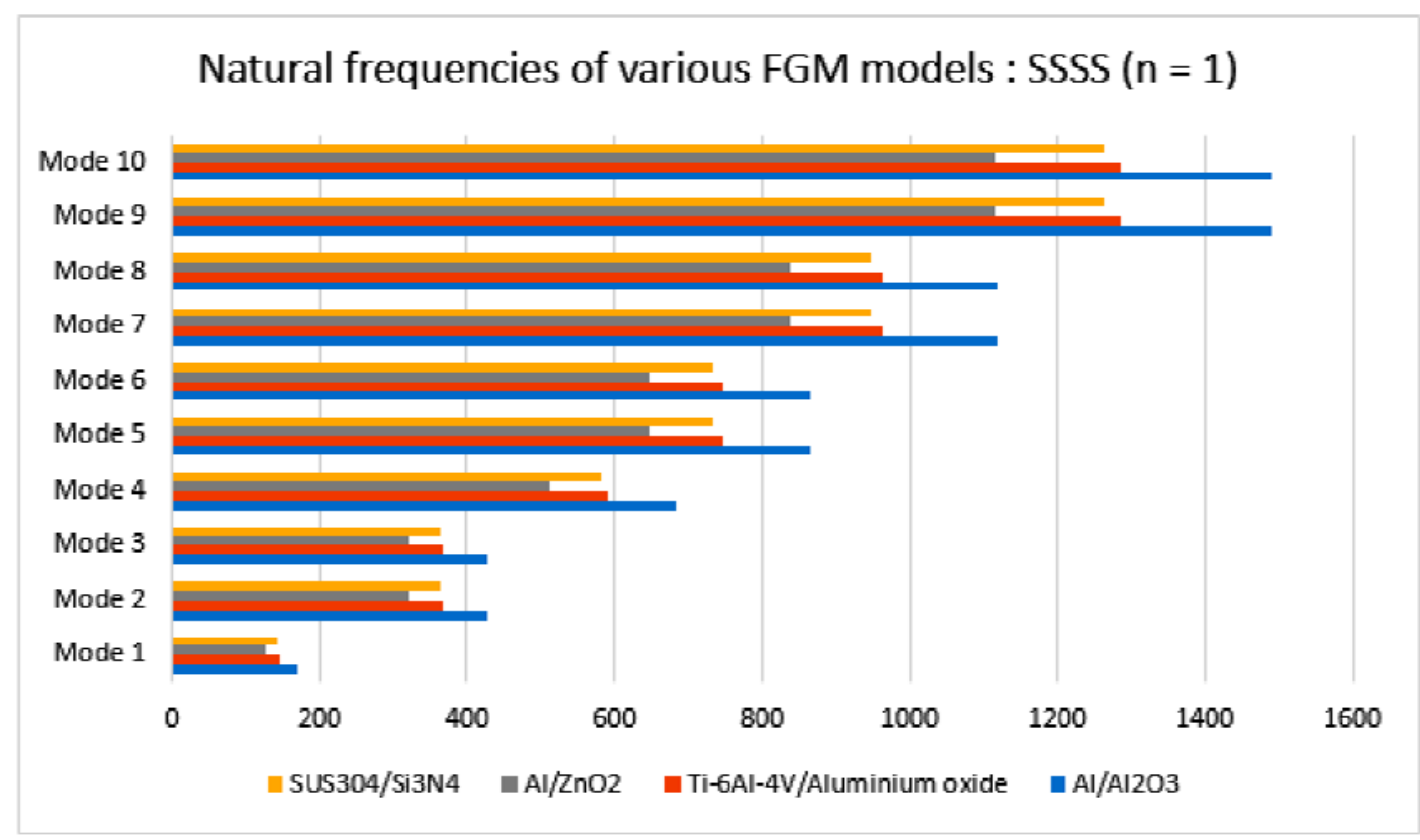

Fig.6. Natural frequencies of the FG platewith SSSS boundary condition.

\subsubsection{Harmonic analysis}

To obtain the FRF plot, harmonic analysis is to be done by providing the range of natural frequency of $0 \mathrm{~Hz}$ to $2000 \mathrm{~Hz}$ and 100 substeps. It will generate the FRF plot (linear) on graph of amplitude to frequency, frequency $(\mathrm{Hz})$ is taken on the $x$-axis and amplitude $(m)$ on the $y$-axis. From this graph we come to know its resonance point. It can be said that the overall response of the system can be known. These frequency response amplitudes can also be reduced by providing a damping constant. In the study, the constant damping ratio of $1 \%$ to $4 \%$ or 0.01 to 0.04 is taken. The effect of the damping constant on the frequency response amplitude for different sets of FG plates with different boundary conditions and different volume fraction exponent is shown in Tabs 7-10, respectively.

Table 7. Effect of the damping constant on the frequency response amplitude for the square $\mathrm{Al} / \mathrm{Al}_{2} \mathrm{O}_{3} \mathrm{FG}$ plate.

\begin{tabular}{|l|l|l|l|l|l|l|}
\hline B.C. & \multicolumn{2}{l|}{ MODE } & \multicolumn{1}{l|}{} \\
\hline & $\boldsymbol{n}$ & $\boldsymbol{D}=\mathbf{0}$ & $\boldsymbol{D}=\mathbf{0 . 0 1}$ & $\boldsymbol{D}=\mathbf{0 . 0 2}$ & $\boldsymbol{D}=\mathbf{0 . 0 3}$ & $\boldsymbol{D}=\mathbf{0 . 0 4}$ \\
\hline & & & & & & \\
\hline CCCC & $n=0$ & 0.0291 & 0.0262 & 0.0203 & 0.0147 & 0.0106 \\
\hline & $n=1$ & 0.0264 & 0.0261 & 0.0249 & 0.0232 & 0.0218 \\
\hline & $n=10$ & 0.0544 & 0.0519 & 0.0456 & 0.0380 & 0.0307 \\
\hline & & & & & & \\
\hline SSSS & $n=0$ & 0.0518 & 0.0496 & 0.0438 & 0.0367 & 0.0299 \\
\hline & $n=1$ & 0.0353 & 0.0350 & 0.0343 & 0.0335 & 0.0331 \\
\hline & $n=10$ & 0.550 & 0.333 & 0.152 & 0.0802 & 0.0482 \\
\hline
\end{tabular}

The FRF plot of amplitude $(m)$ to frequency $(\mathrm{Hz})$ for $\mathrm{Al} / \mathrm{Al}_{2} \mathrm{O}_{3} \mathrm{FG}$ plate at a different damping ratio is shown on linear scale. It shows that on increasing the value of damping constant, the maximum amplitude at resonance point is going down. 
Figs 7a-7e show the FRF plots without damping $(D=0)$ and with damping $(D=0.01$ to 0.04$)$ for $\mathrm{Al} / \mathrm{Al}_{2} \mathrm{O}_{3} \mathrm{FG}$ plate at CCCC boundary condition.

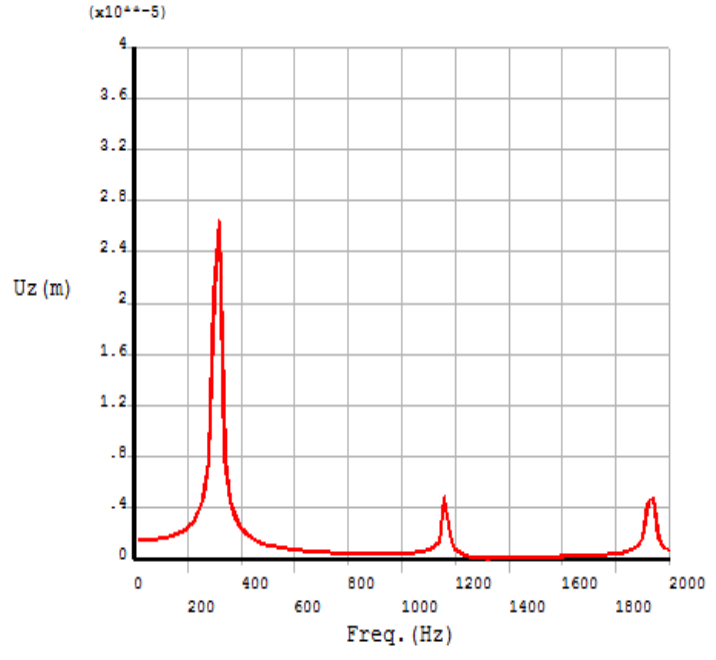

Fig.7a

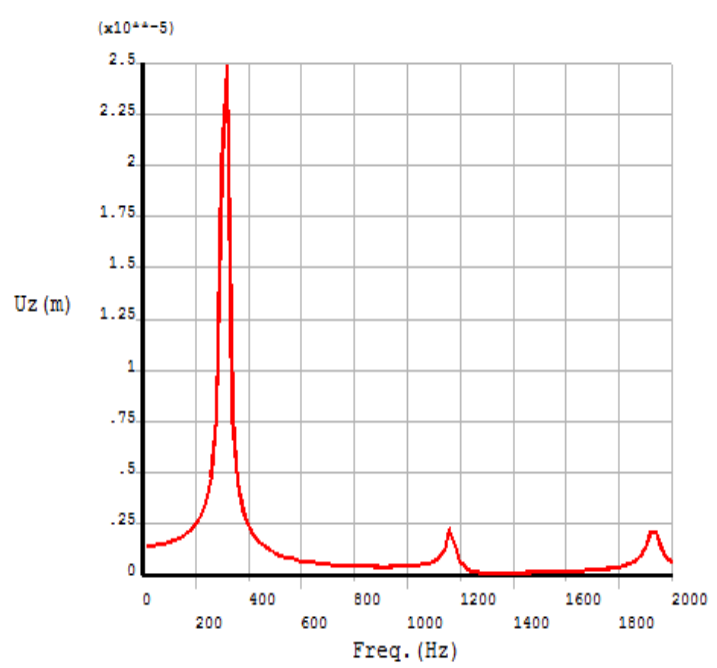

Fig.7c

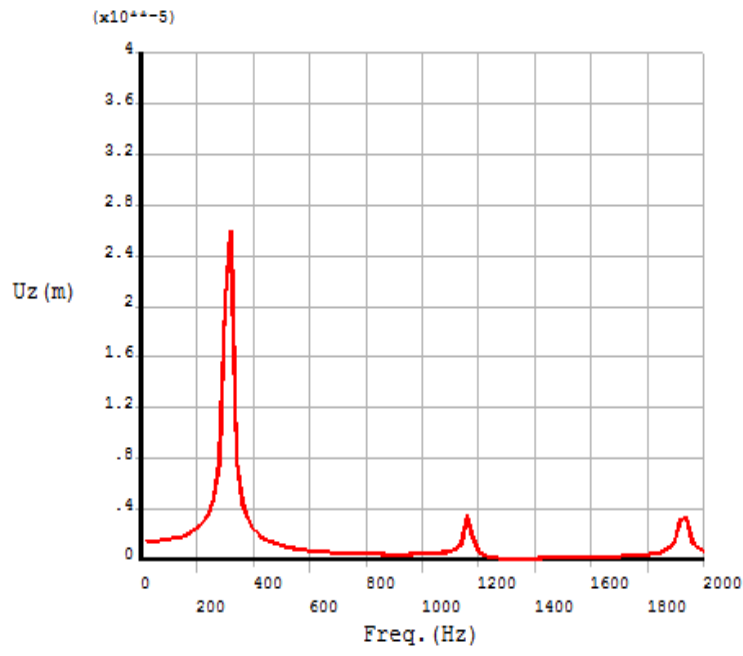

Fig. $7 \mathrm{~b}$

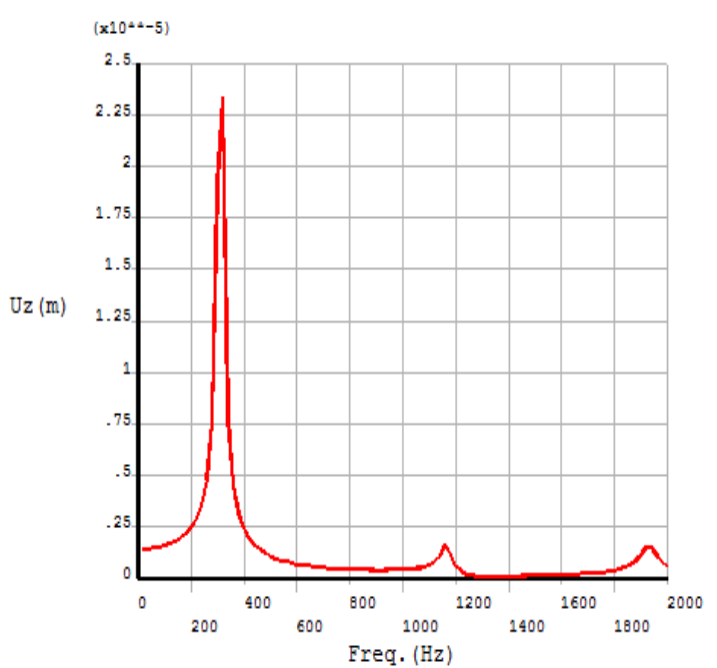

Fig.7d

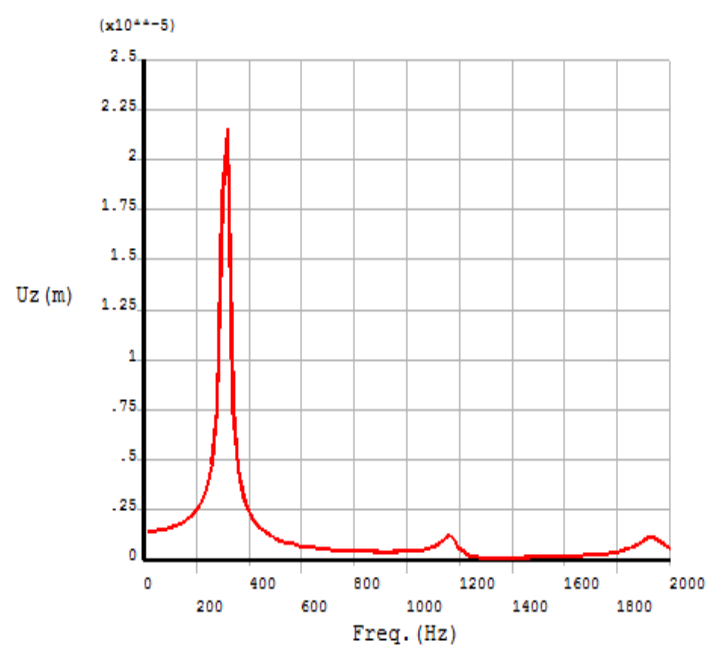

Fig.7e 
Figs 8a-8e shows the FRF plots without damping $(D=0)$ and with damping $(D=0.01$ to 0.04$)$ for $\mathrm{Al} / \mathrm{Al}_{2} \mathrm{O}_{3} \mathrm{FG}$ plate at SSSS boundary condition.

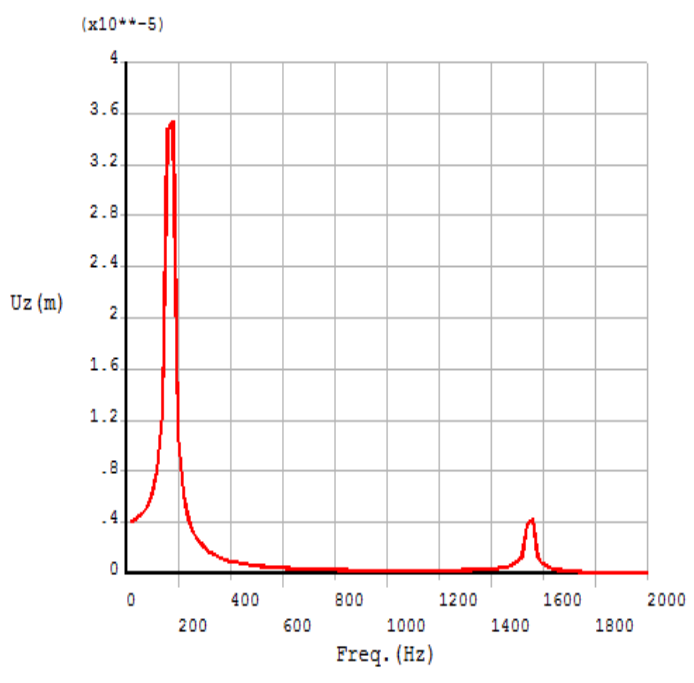

Fig.8a

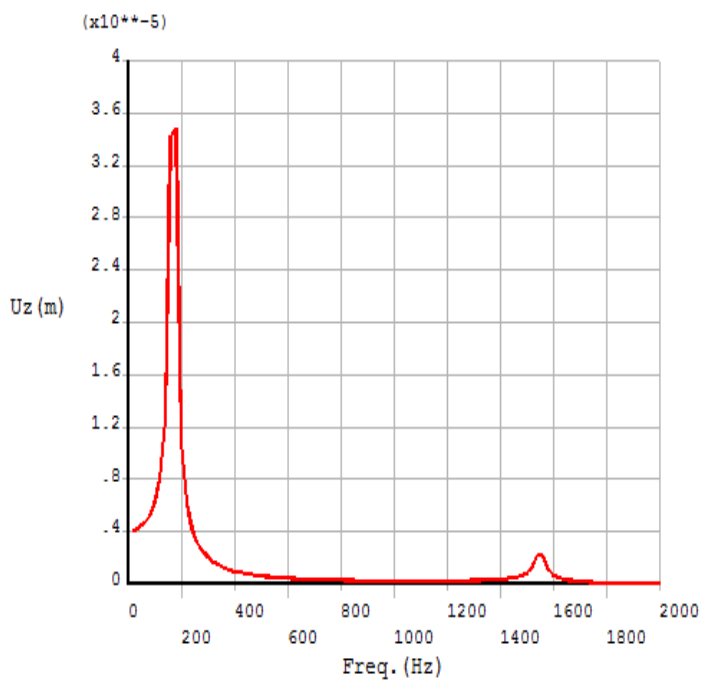

Fig. $8 \mathrm{c}$

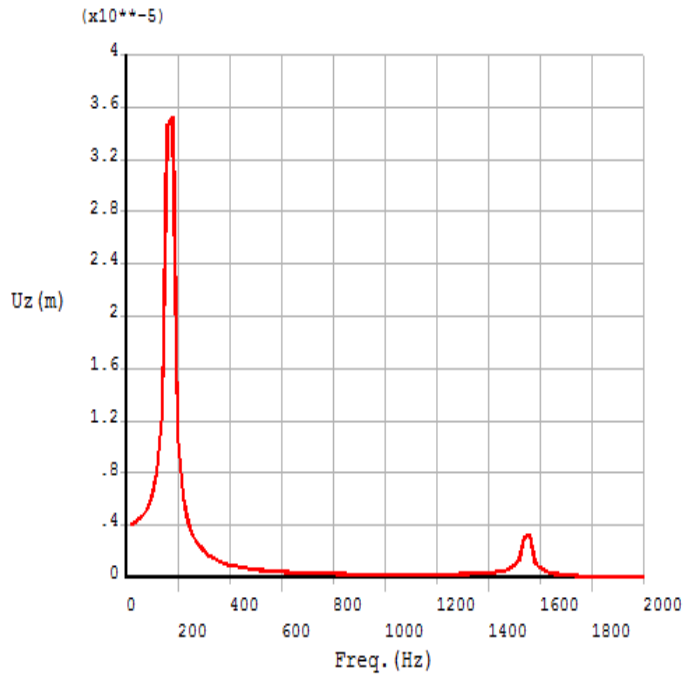

Fig. $8 b$

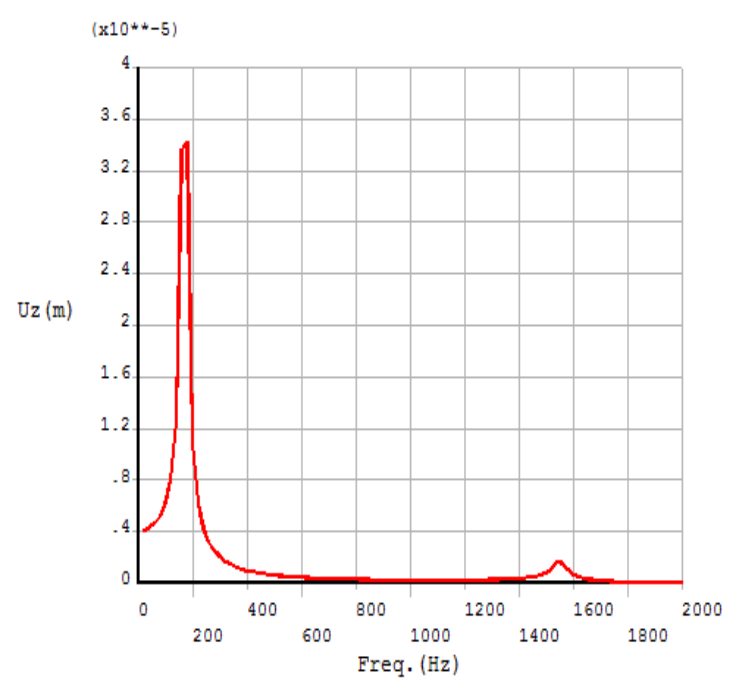

Fig.8d

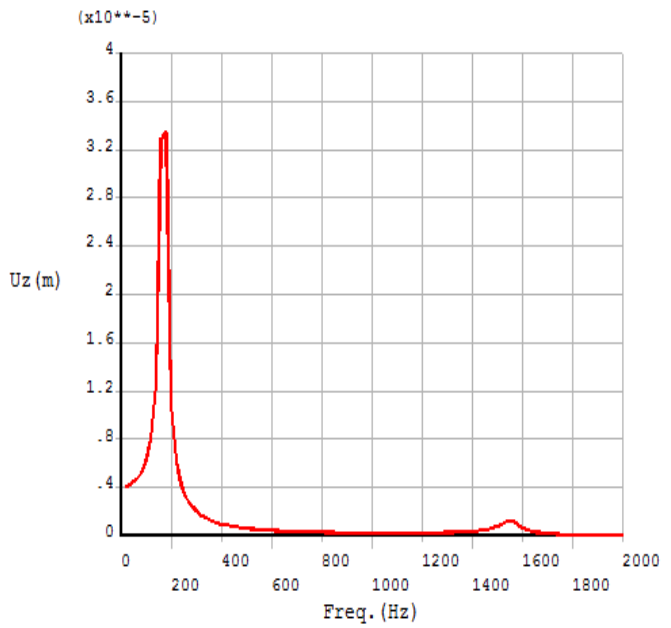

Fig.8e 
Table 8. Effect of the damping constant on the frequency response amplitude for the square Ti-6Al4V/Aluminum oxide FG plate.

\begin{tabular}{|l|l|l|l|l|l|l|}
\hline B.C. & \multicolumn{2}{l|}{ MODE } & \multicolumn{1}{l|}{} \\
\hline & $\boldsymbol{n}$ & $\boldsymbol{D}=\mathbf{0}$ & $\mathbf{D}=\mathbf{0 . 0 1}$ & $\boldsymbol{D}=\mathbf{0 . 0 2}$ & $\boldsymbol{D}=\mathbf{0 . 0 3}$ & $\boldsymbol{D}=\mathbf{0 . 0 4}$ \\
\hline & & & & & & \\
\hline CCCC & $n=0$ & 0.1141 & 0.0534 & 0.0217 & 0.0108 & 0.0077 \\
\hline & $n=1$ & 0.0258 & 0.0253 & 0.0245 & 0.0231 & 0.0217 \\
\hline & $n=10$ & 0.1602 & 0.1056 & 0.0521 & 0.0282 & 0.0171 \\
\hline & & & & & & \\
\hline SSSS & $n=0$ & 0.0401 & 0.0394 & 0.0374 & 0.0344 & 0.0310 \\
\hline & $n=1$ & 0.0482 & 0.0478 & 0.0473 & 0.0459 & 0.0440 \\
\hline & $n=10$ & 0.304 & 0.244 & 0.153 & 0.0949 & 0.0618 \\
\hline
\end{tabular}

Figs 9a-9e shows the FRF plots without damping $(D=0)$ and with damping ( $D=0.01$ to 0.04 ) for Ti-6Al4V/Aluminium oxide FG plate at CCCC boundary condition.

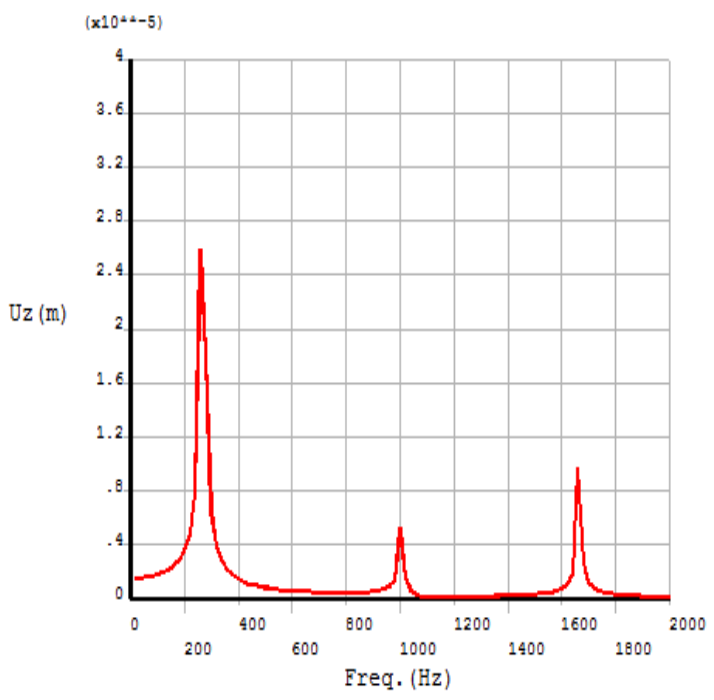

Fig.9a

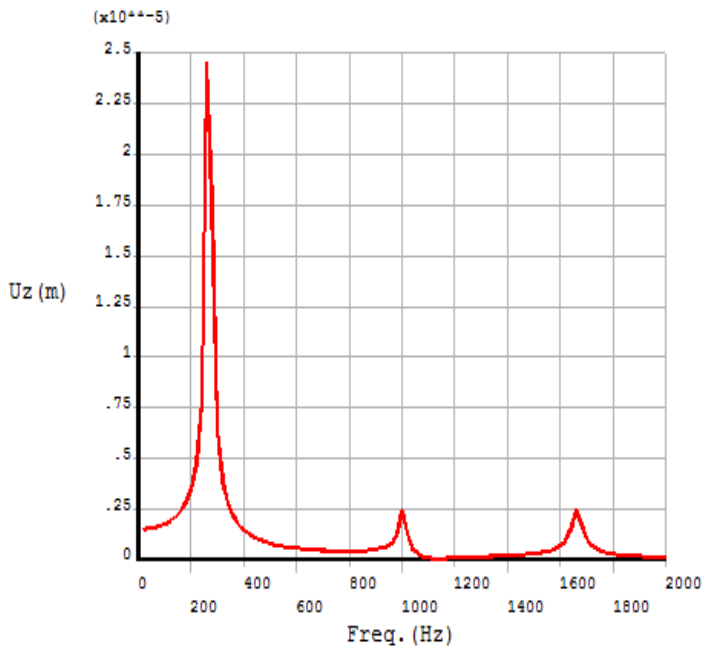

Fig.9c

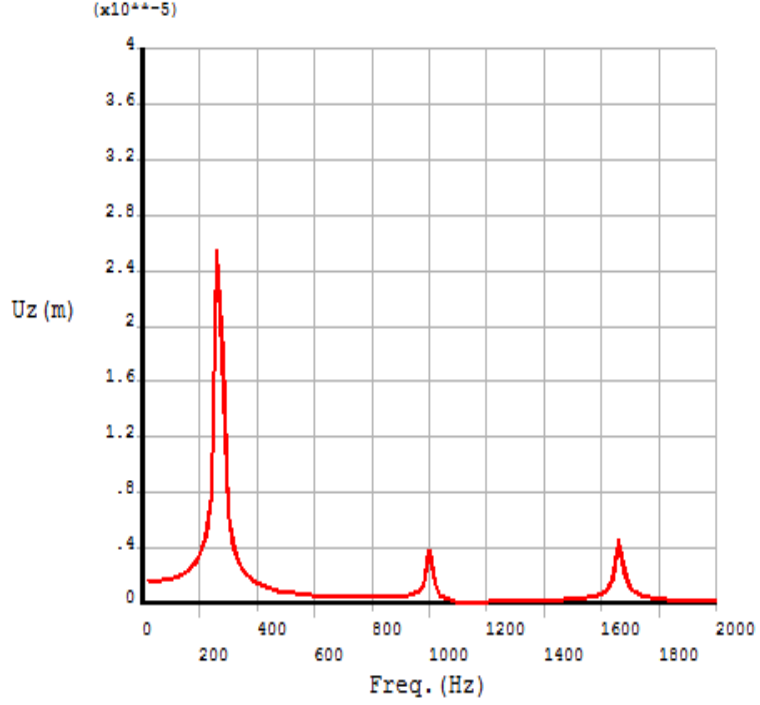

Fig.9b

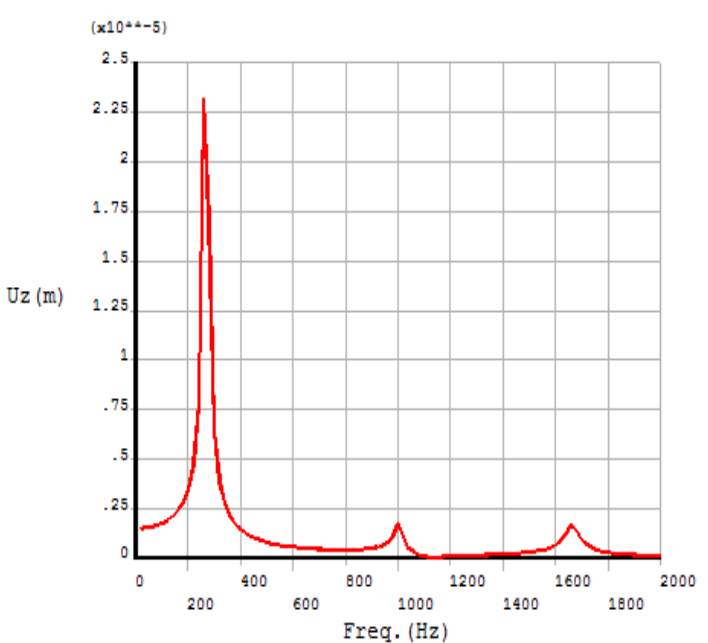

Fig.9d 


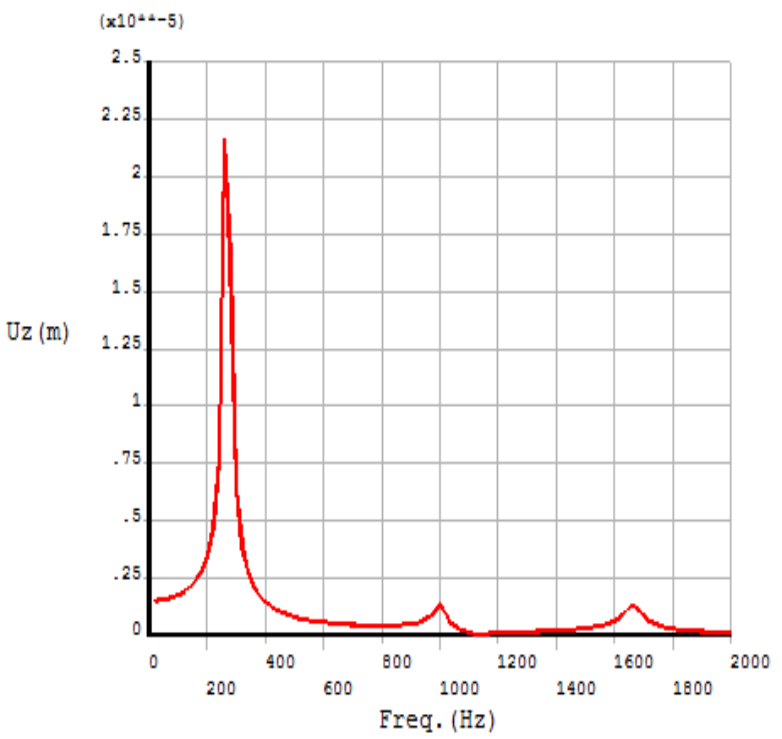

Fig.9e

Figs 10a-10e shows the FRF plots without damping $(D=0)$ and with damping ( $D=0.01$ to 0.04$)$ for Ti-6Al4V/Aluminium oxide FG plate at SSSS boundary condition.

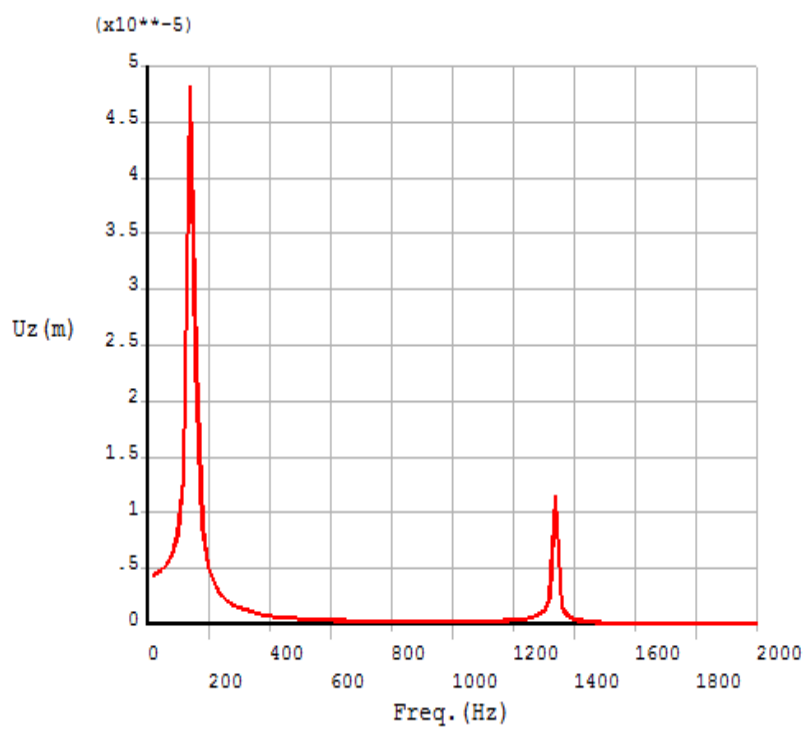

Fig. 10a

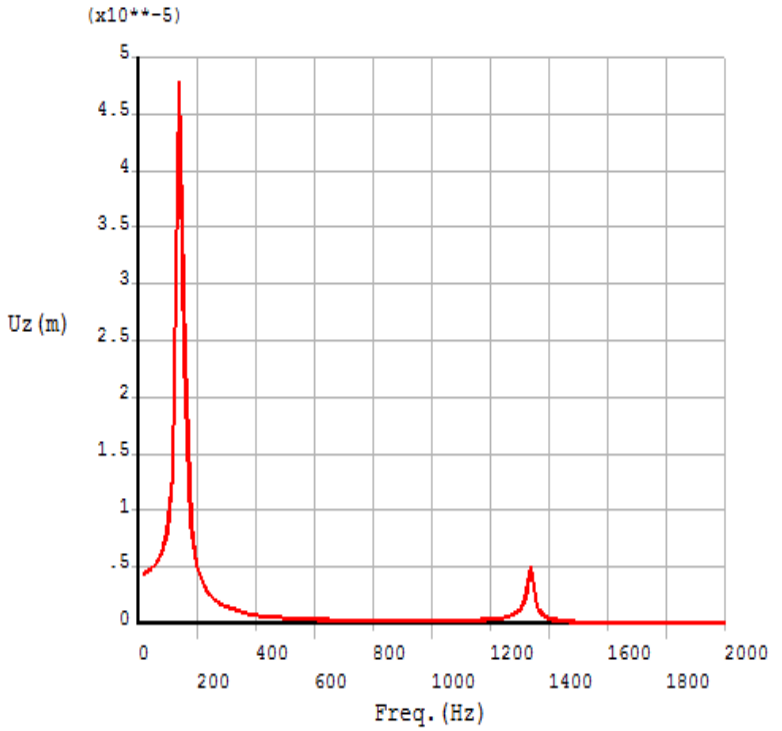

Fig. 10b 


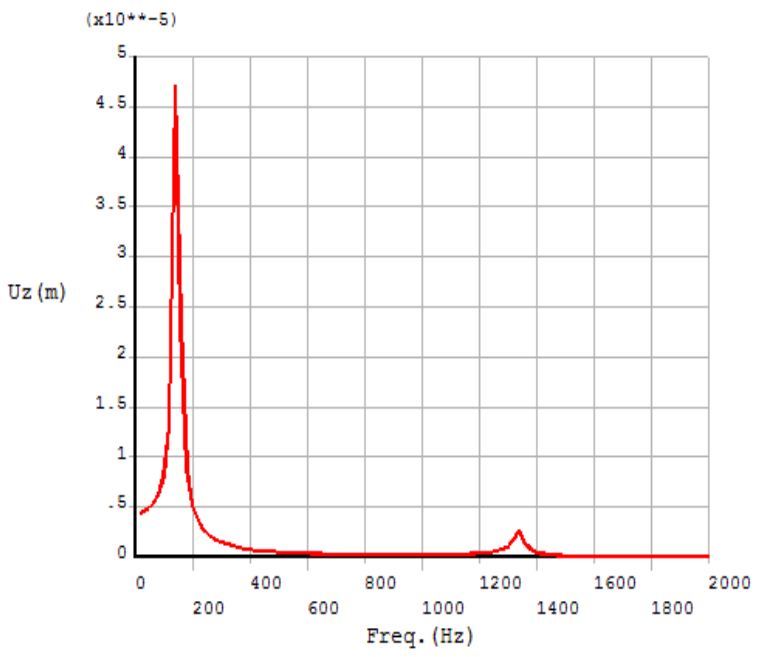

Fig.10c

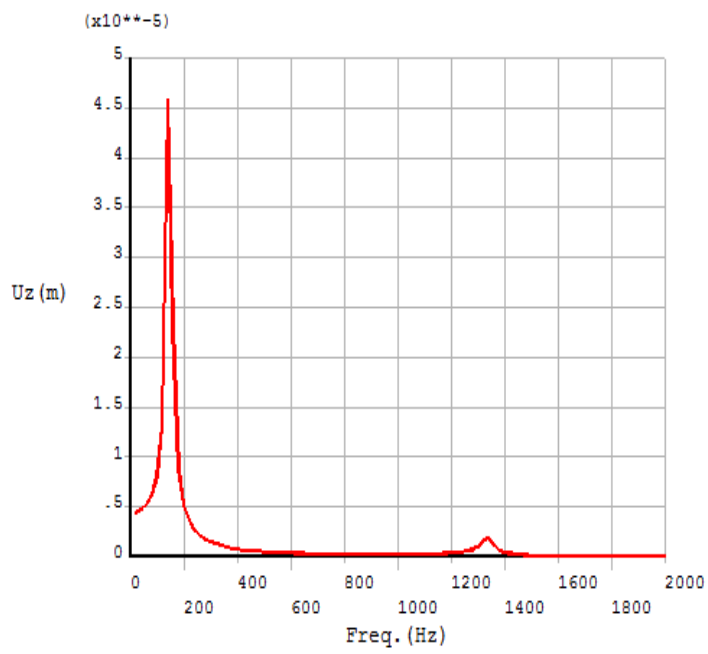

Fig.10d

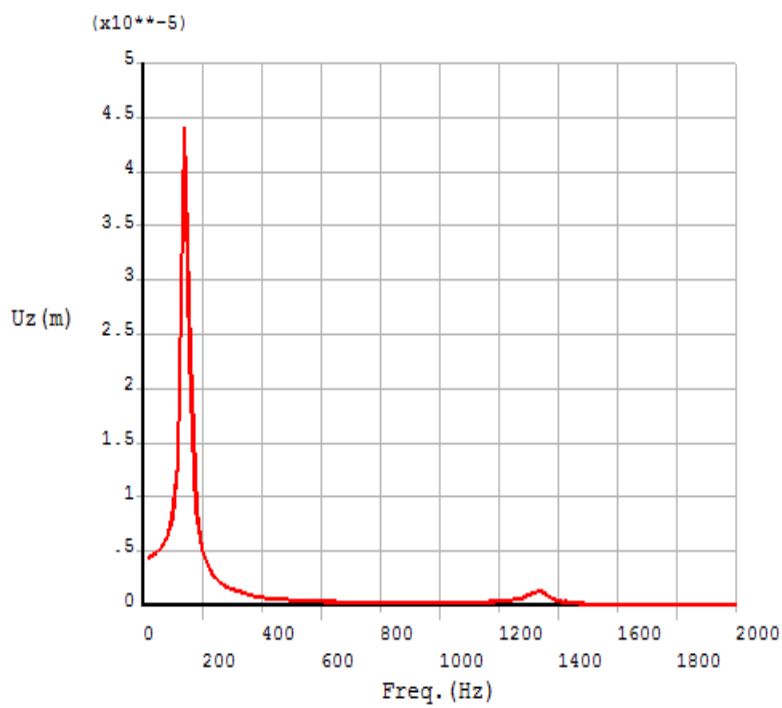

Fig.10e

Table 9. Effect of damping constant on the frequency response amplitude for square $\mathrm{Al} / \mathrm{ZrO}_{2} \mathrm{FG}$ plate.

\begin{tabular}{|l|l|l|l|l|l|l|}
\hline B.C. & \multicolumn{2}{l|}{$M O D E$} & $\boldsymbol{D}=\mathbf{0 . 0 2}$ & $\boldsymbol{D}=\mathbf{0 . 0 3}$ & $\boldsymbol{D}=\mathbf{0 . 0 4}$ \\
\hline & $\boldsymbol{n}$ & $\boldsymbol{D}=\mathbf{0}$ & $\boldsymbol{D}=\mathbf{0 . 0 1}$ & $\boldsymbol{D}$ & & \\
\hline CCCC & $n=0$ & 0.0530 & 0.0501 & 0.0430 & 0.0348 & 0.0275 \\
\hline & $n=1$ & 0.0496 & 0.0487 & 0.0473 & 0.0445 & 0.0420 \\
\hline & $n=10$ & 0.0411 & 0.0406 & 0.0392 & 0.0371 & 0.0346 \\
\hline & & & & & & \\
\hline SSSS & $n=0$ & 0.0847 & 0.0831 & 0.0787 & 0.0722 & 0.0648 \\
\hline & $n=1$ & 0.0732 & 0.0728 & 0.0722 & 0.0703 & 0.0682 \\
\hline & $n=10$ & 0.1172 & 0.1158 & 0.1118 & 0.1057 & 0.0981 \\
\hline
\end{tabular}

Figs 11a - 11e shows the FRF plots without damping $(D=0)$ and with damping $(D=0.01$ to 0.04$)$ for $\mathrm{Al} / \mathrm{ZrO}_{2} \mathrm{FG}$ plate at $\mathrm{CCCC}$ boundary condition. 


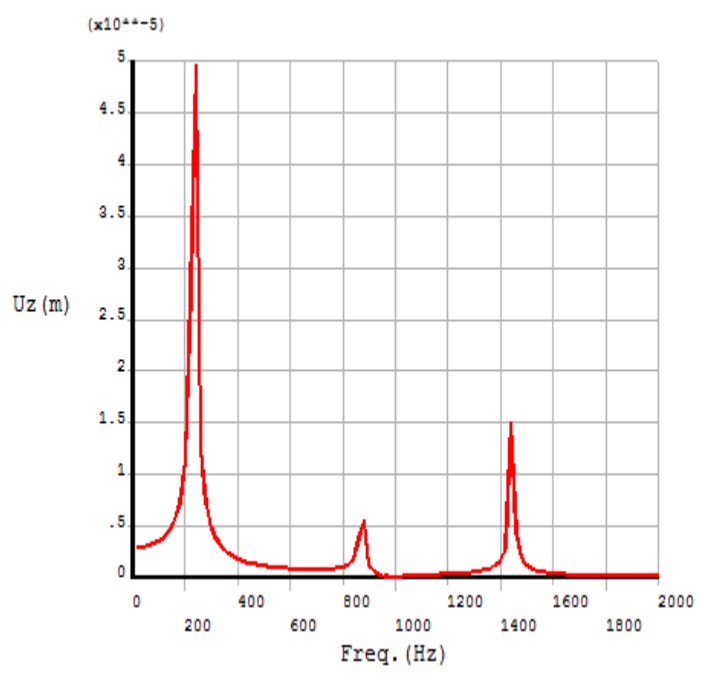

Fig.11a

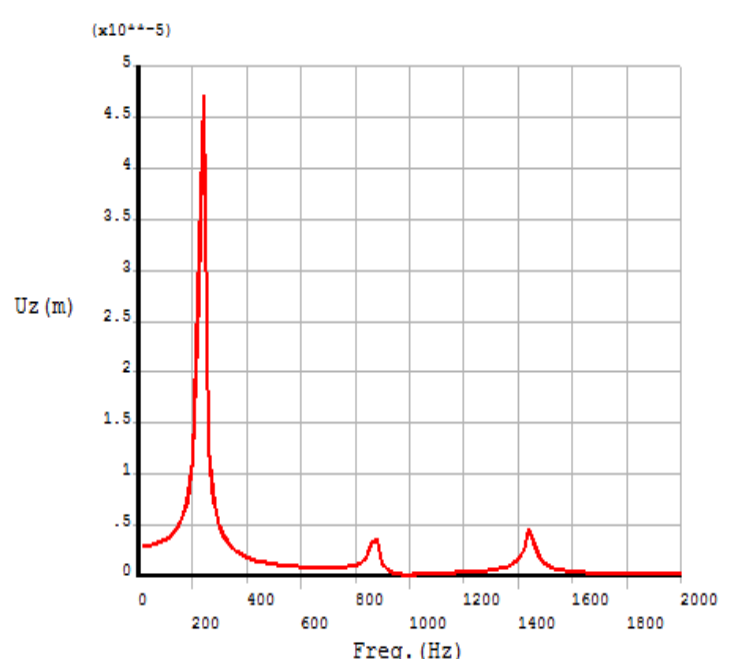

Fig.11c

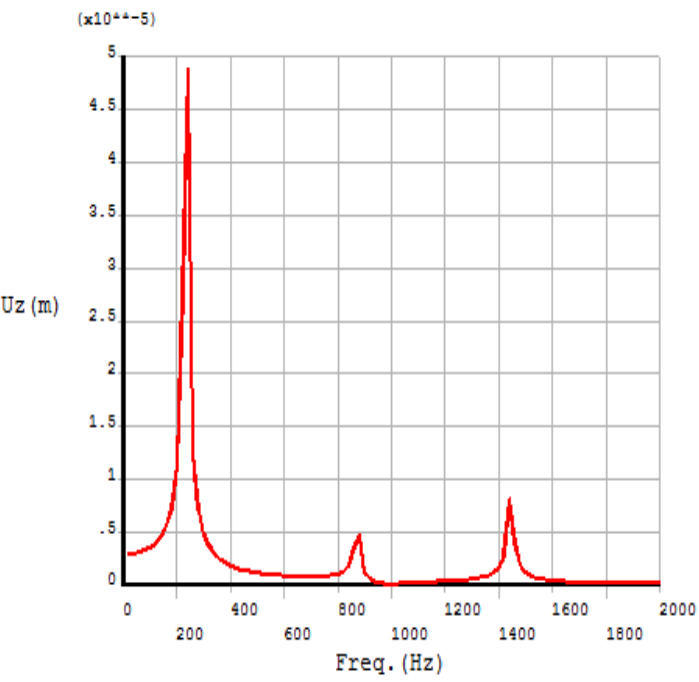

Fig. 11b

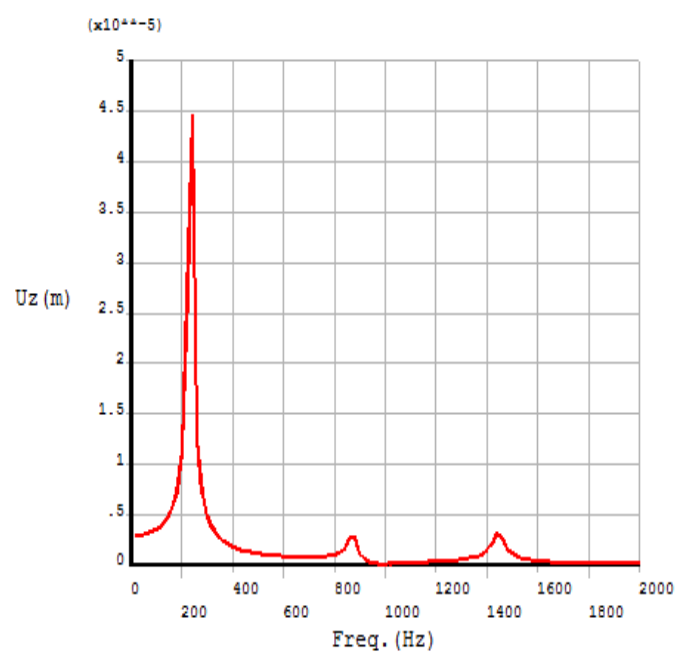

Fig.11d

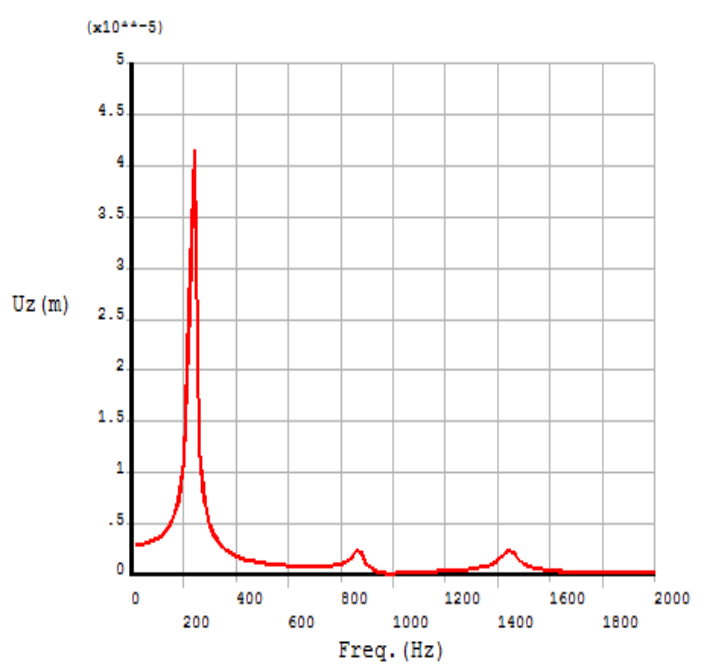

Fig.11e 
Figs 12a-12e shows the FRF plots without damping $(D=0)$ and with damping ( $D=0.01$ to 0.04$)$ for $\mathrm{Al} / \mathrm{ZrO}_{2} \mathrm{FG}$ plate at SSSS boundary condition.

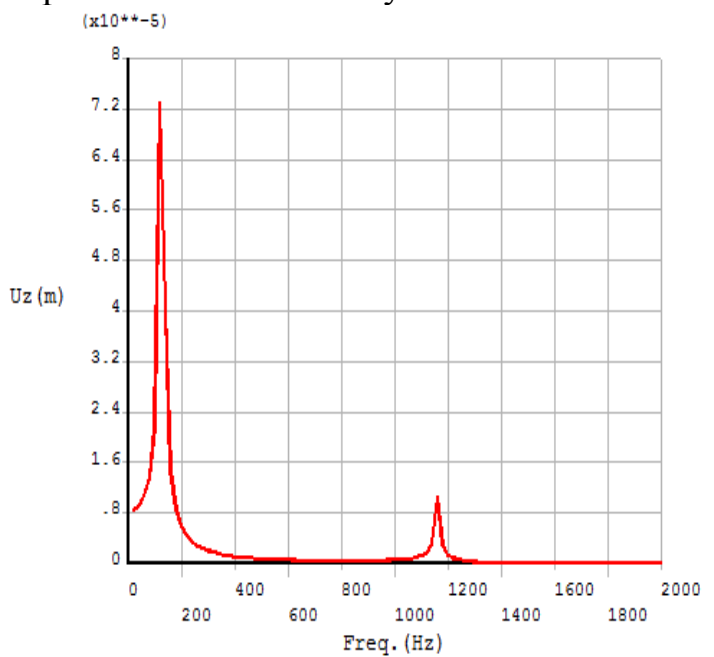

Fig.12a

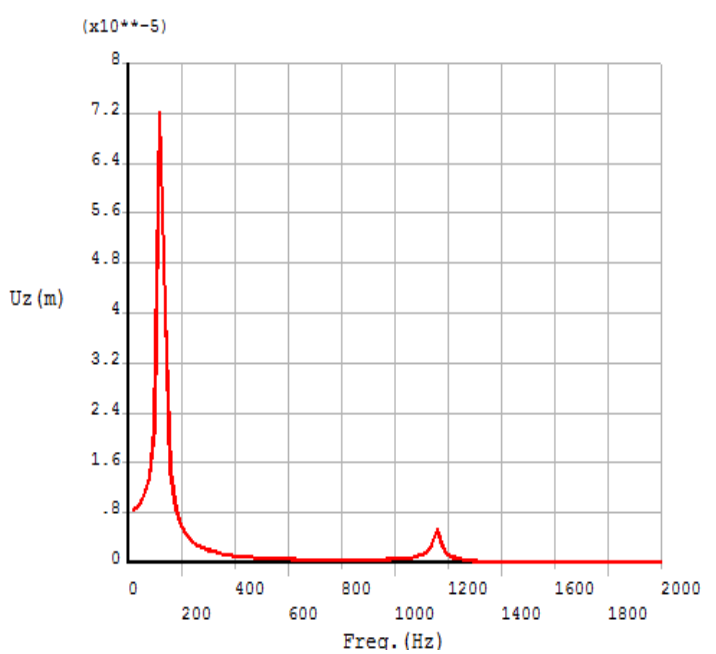

Fig.12c

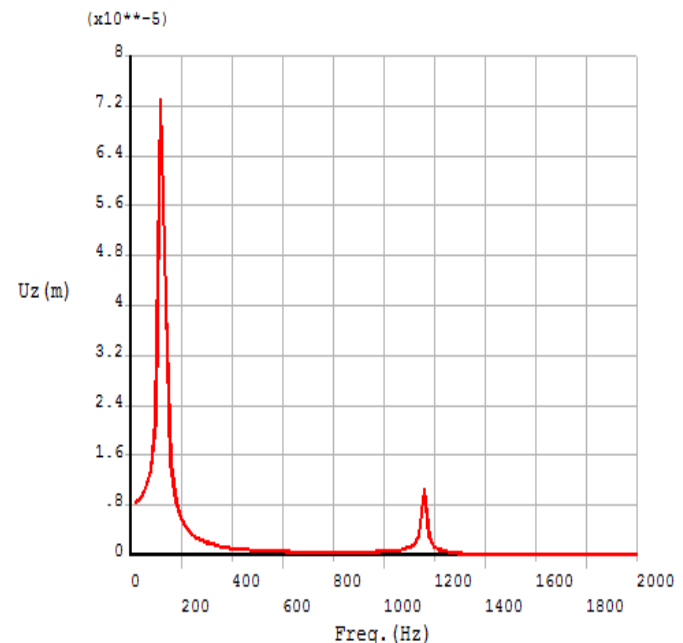

Fig. $12 b$

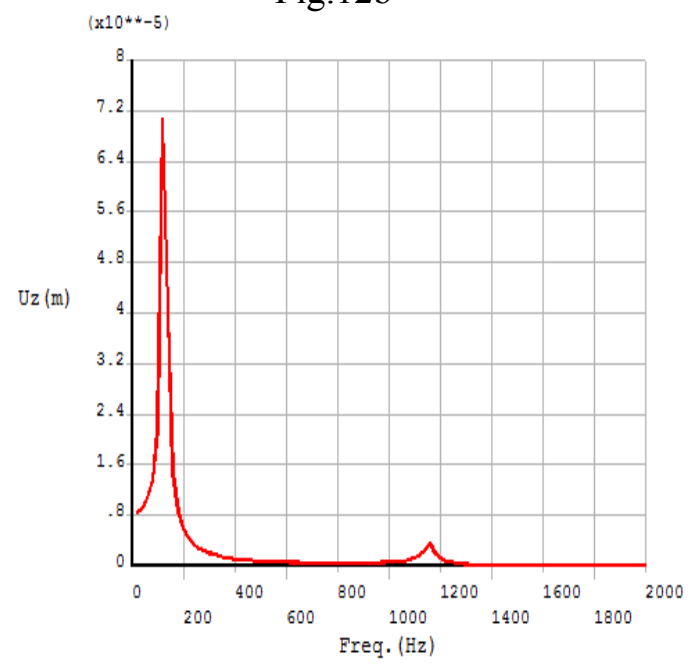

Fig.12d

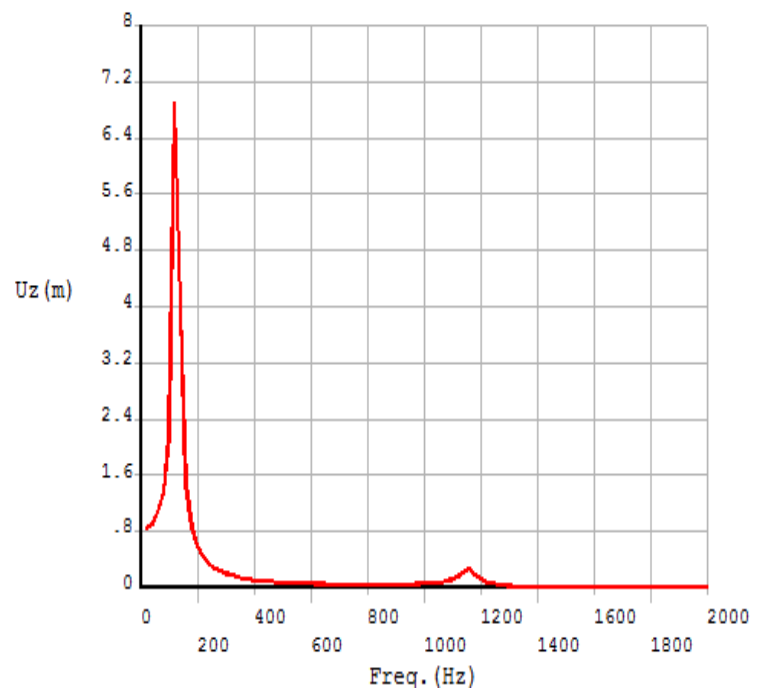

Fig. 12e 
Table 10. Effect of damping constant on the frequency response amplitude for the square $\mathrm{SUS} 304 / \mathrm{Si}_{3} \mathrm{~N}_{4} \mathrm{FG}$ plate.

\begin{tabular}{|l|l|l|l|l|l|l|}
\hline B.C. & \multicolumn{2}{l|}{$M O D E$} & $\boldsymbol{D}=\mathbf{0 . 0 2}$ & $\boldsymbol{D}=\mathbf{0 . 0 3}$ & $\boldsymbol{D}=\mathbf{0 . 0 4}$ \\
\hline & $\boldsymbol{n}$ & $\boldsymbol{D}=\mathbf{0}$ & $\boldsymbol{D}=\mathbf{0 . 0 1}$ & $\boldsymbol{D}$ & & \\
\hline CCCC & $n=0$ & 0.0460 & 0.0244 & 0.0209 & 0.0169 & 0.0133 \\
\hline & $n=1$ & 0.0450 & 0.0426 & 0.0368 & 0.0311 & 0.0265 \\
\hline & $n=10$ & 0.0446 & 0.0408 & 0.0323 & 0.0240 & 0.0177 \\
\hline & & & & & & \\
\hline SSSS & $n=0$ & 0.0654 & 0.0624 & 0.0548 & 0.0455 & 0.0368 \\
\hline & $n=1$ & 0.0597 & 0.0580 & 0.0563 & 0.0535 & 0.0494 \\
\hline & $n=10$ & 0.1536 & 0.1343 & 0.0964 & 0.0656 & 0.0453 \\
\hline
\end{tabular}

Figs 13a-13e shows the FRF plots without damping $(D=0)$ and with damping $(D=0.01$ to 0.04$)$ for $\mathrm{SUS} 304 / \mathrm{Si}_{3} \mathrm{~N}_{4} \mathrm{FG}$ plate at CCCC boundary condition.

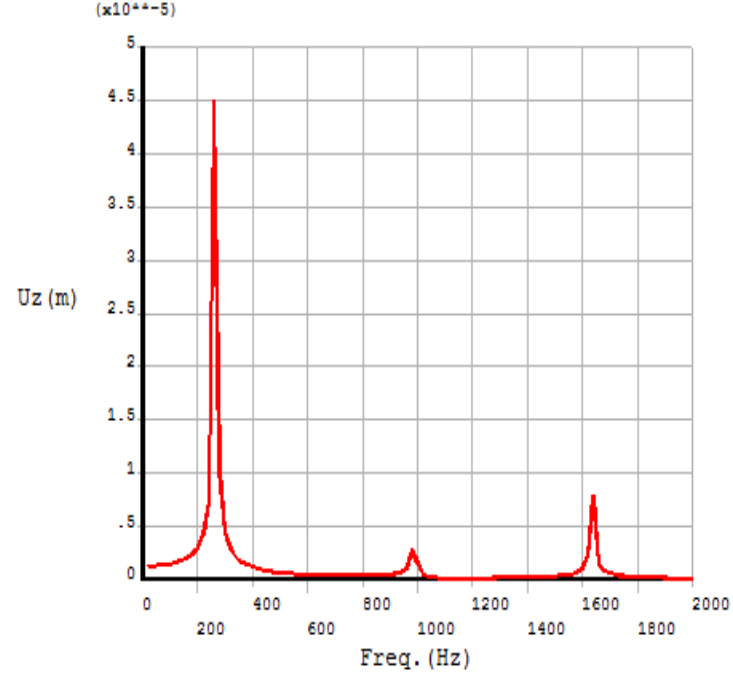

Fig.13a

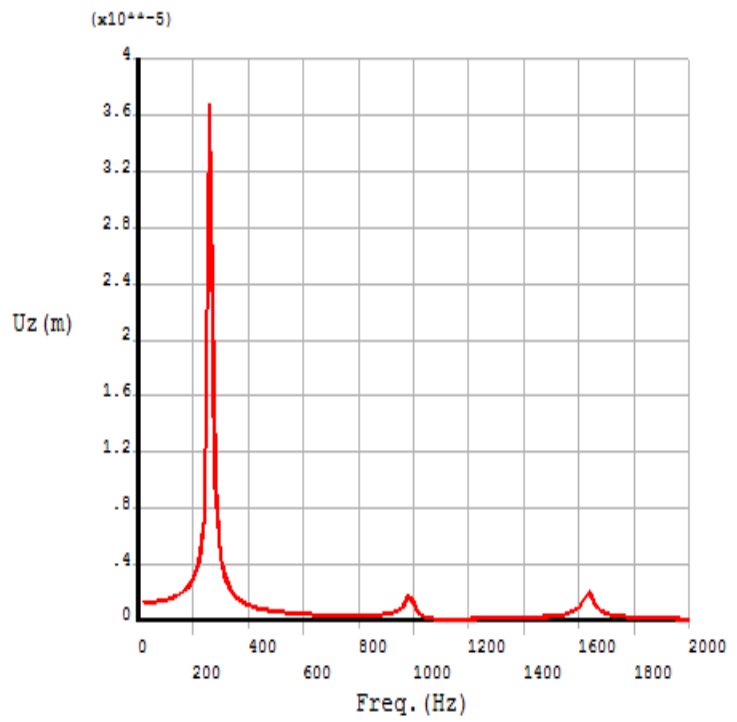

Fig.13c

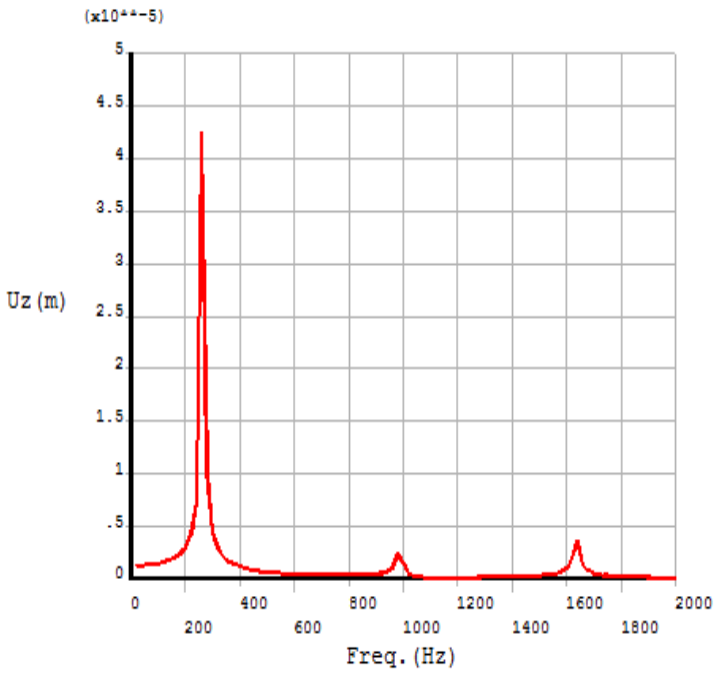

Fig. 13b

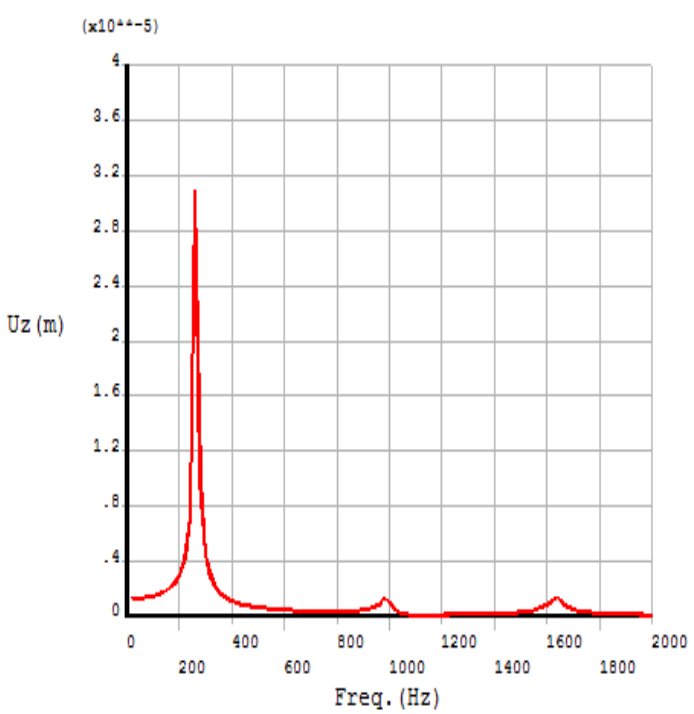

Fig.13d 


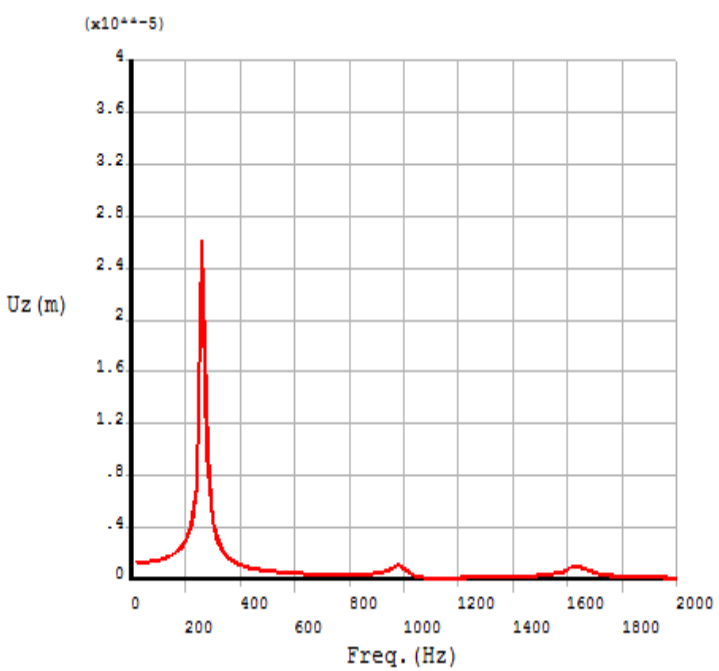

Fig.13e

Figs $14 \mathrm{a}-14 \mathrm{e}$ shows the FRF plots without damping $(D=0)$ and with damping $(D=0.01$ to 0.04$)$ for SUS304/ $\mathrm{Si}_{3} \mathrm{~N}_{4}$ FG plate at SSSS boundary condition.

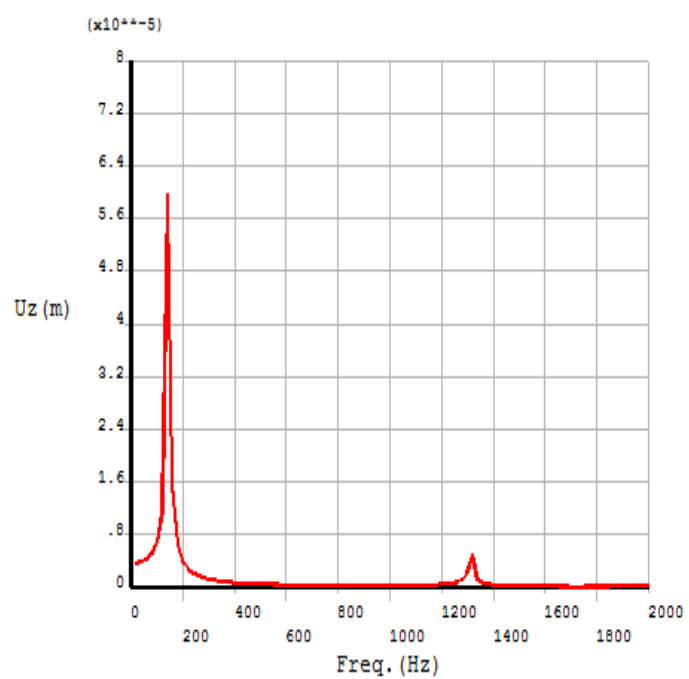

Fig. 14a

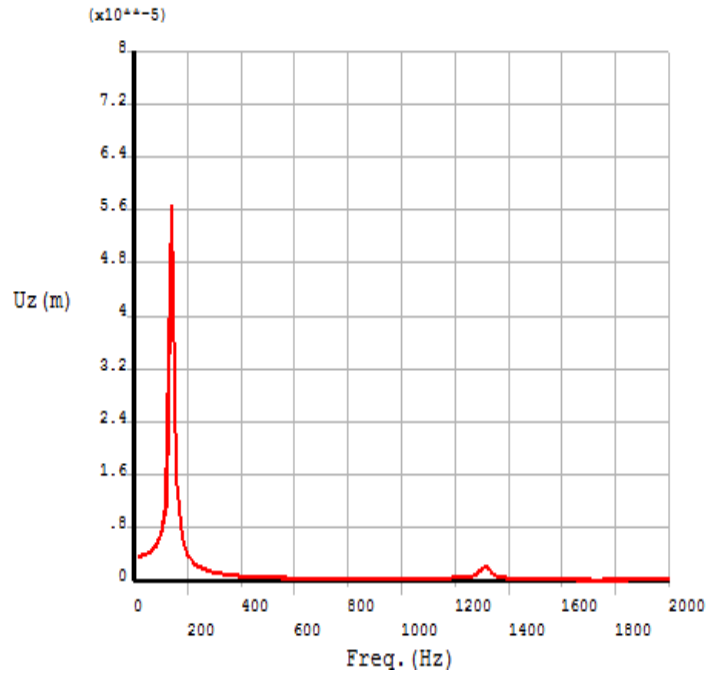

Fig. 14c

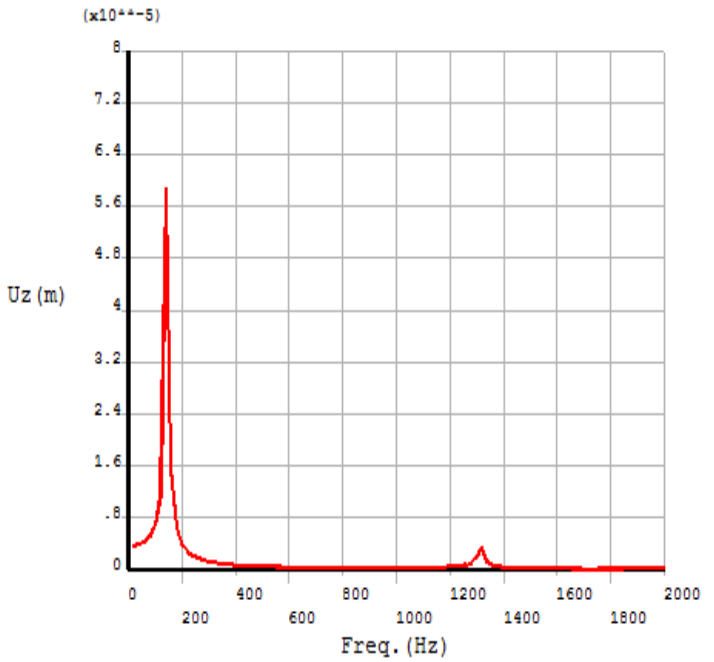

Fig. 14b

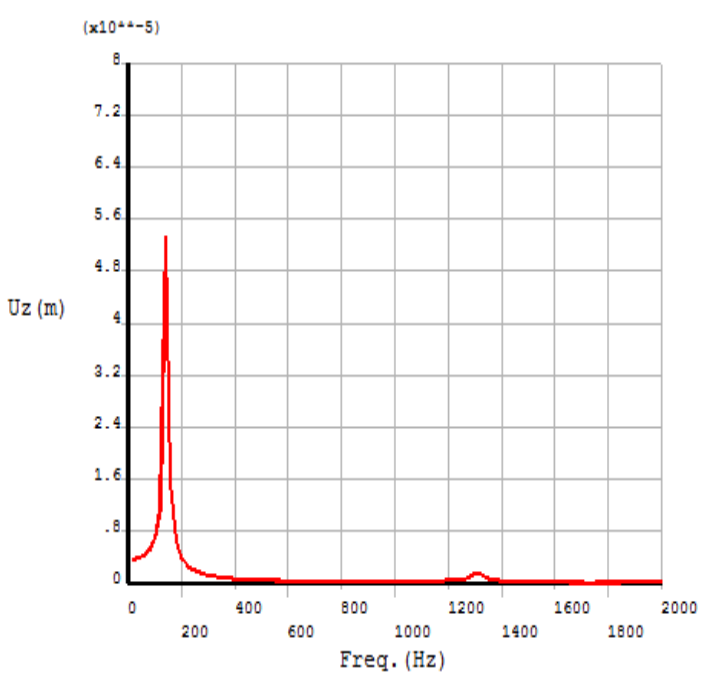

Fig.14d 


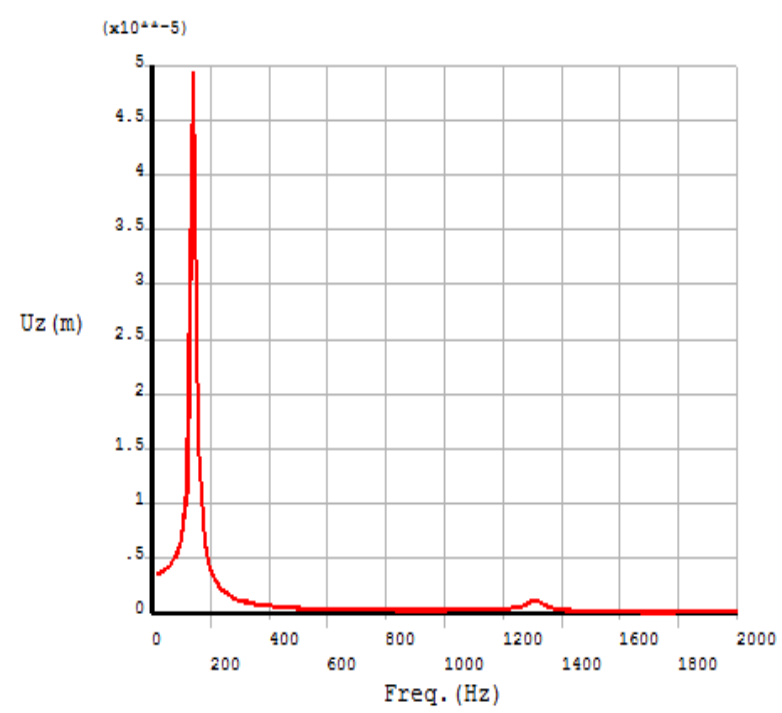

Fig.14e

\section{Verification of harmonic analysis}

A square plate with all edge fixed boundary condition, of dimension $304.8 \times 304.8 \times 2 \mathrm{~mm}$ of steel material with properties of $\rho=7.86 \times 10^{-9}$ tonne $/ \mathrm{mm}^{3}, v=0.3, Y=2 e^{5} \mathrm{MPa}$ was created. A force of $1 \mathrm{~N}$ is applied at the node location $(75 \mathrm{~mm}, 152.4 \mathrm{~mm})$ of all the plates. The frequency range is given from 0 to $3000 \mathrm{~Hz}$. Harmonic analysis of the plate is solved in ANSYS 15 software using the full method. The full method uses the full system matrices to calculate the harmonic response (no matrix reduction). During the analysis, it is found that the fundamental mode for the plate was excited at the frequency $188.94 \mathrm{~Hz}$, where the highest value of amplitude $1.8 e-2 \mathrm{~mm}$ is obtained (as shown in Tab.11).

Table 11. Verification of the frequency response amplitude for the square steel plate.

\begin{tabular}{|l|l|l|l|}
\hline B.C. & Mode & Frequency (Hz) & Amplitude (mm) \\
\hline CCCC & $\begin{array}{l}\text { Mode 1, Present } \\
\begin{array}{l}\text { Mode 1, Khan } \\
{[11]}\end{array}\end{array}$ & 188.94 & $1.8 e-2$ \\
\hline & Error & $0.06 \%$ & $1.8 e-2$ \\
\hline
\end{tabular}

Harmonic analysis of the plates gives the frequency response amplitudes at their fundamental mode. Results of harmonic analysis show that the plate $\mathrm{Al} / \mathrm{ZrO}_{2}$ has the highest amplitude value and the plate $\mathrm{Al} / \mathrm{Al}_{2} \mathrm{O}_{3}$ has the lowest amplitude value. Also, on providing the damping constant, the maximum amplitude value at the resonance point on decreases, and it further on decreases, as the value of damping constant is increased. The effect of damping on frequency response amplitude of the FG models with CCCC boundary condition is shown in Fig.15. 


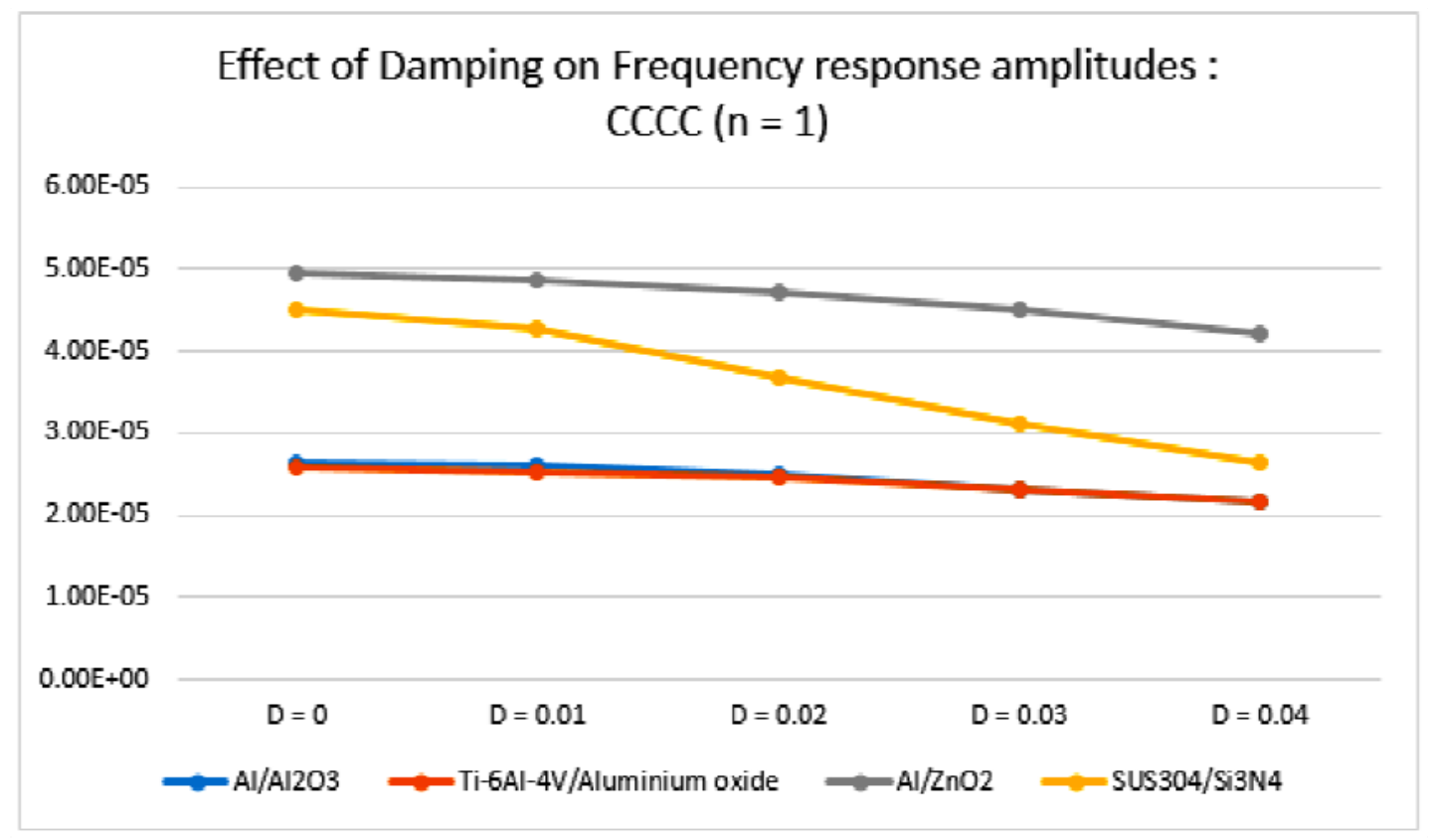

Fig.15. Effect of damping on FG plates with CCCC boundary condition.

Effect of damping on frequency response amplitude of the FG models with SSSS boundary condition is shown in Fig. 16.

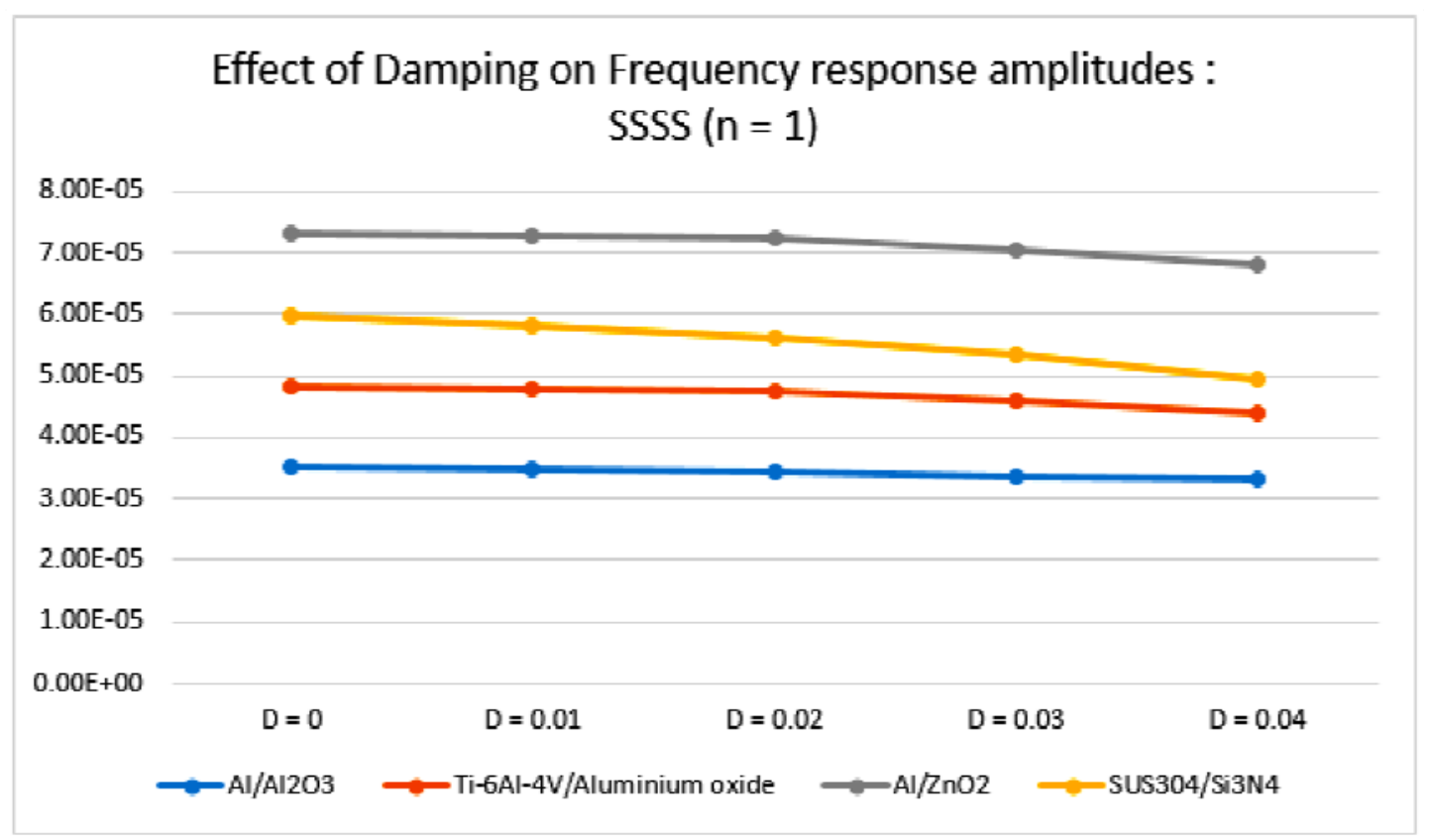

Fig.16. Effect of damping on FG plates with SSSS boundary condition.

\section{Conclusion}

In this study, vibration and harmonic analyses of FGM plates are mode. The effective material properties of functionally graded materials for the plate structures are assumed to vary continuously through 
the plate thickness and are graded in the plate thickness direction according to a volume fraction power law distribution. Four functionally graded plates of different sets of materials are considered and their natural frequencies and frequency response amplitude at the fundamental mode are determined, also effects of damping on dynamic characteristics of the plate are shown in the study. Convergence tests and comparison studies have been carried out with the commercially available software (ANSYS). A four noded layered shell element (SHELL181) is used throughout the problem. The obtained results are in good agreement with those available in the literature for different volume fraction indices, thickness ratios, aspect ratios and different support conditions. The following concluding remarks can be made for thin to thick FGM plates.

$>$ During the analysis, it was found that all the FGP combinations show a similar behaviour, with the frequencies dropping as the volume fraction exponent increases.

$>$ Results of modal analysis show that the natural frequencies for the plates Ti-6Al-4V/Aluminium oxide, and SUS304/Si ${ }_{3} \mathrm{~N}_{4}$ nearly overlap, whereas the plate $\mathrm{Al} / \mathrm{Al}_{2} \mathrm{O}_{3}$ has the highest values and the plate $\mathrm{Al} / \mathrm{ZrO}_{2}$ has the lowest.

For all boundary conditions, vibration amplitude increases as the volume fraction index increases.

Results of harmonic analysis show the plate $\mathrm{Al} / \mathrm{ZrO}_{2}$ has the highest amplitude values and the plate $\mathrm{Al} / \mathrm{Al}_{2} \mathrm{O}_{3}$ has the lowest values.

Also, on providing the damping constant, the maximum amplitude value at the resonance point decreases, and it further decreases, as the value of the damping constant is increased. So it becomes very important to consider the damping constant in the plate design. It helps in vibration control, noise reduction, stability of the system, fatigue and impact resistance.

\section{Future scope}

Different geometric structures can be modelled such as cylindrical, spherical, conical, hyperboloid etc.

Temperature dependent material property can be considered.

$>$ Different types of analysis such as non-linear, buckling, post buckling, etc., can also be performed using the presented model.

\section{Nomenclature}

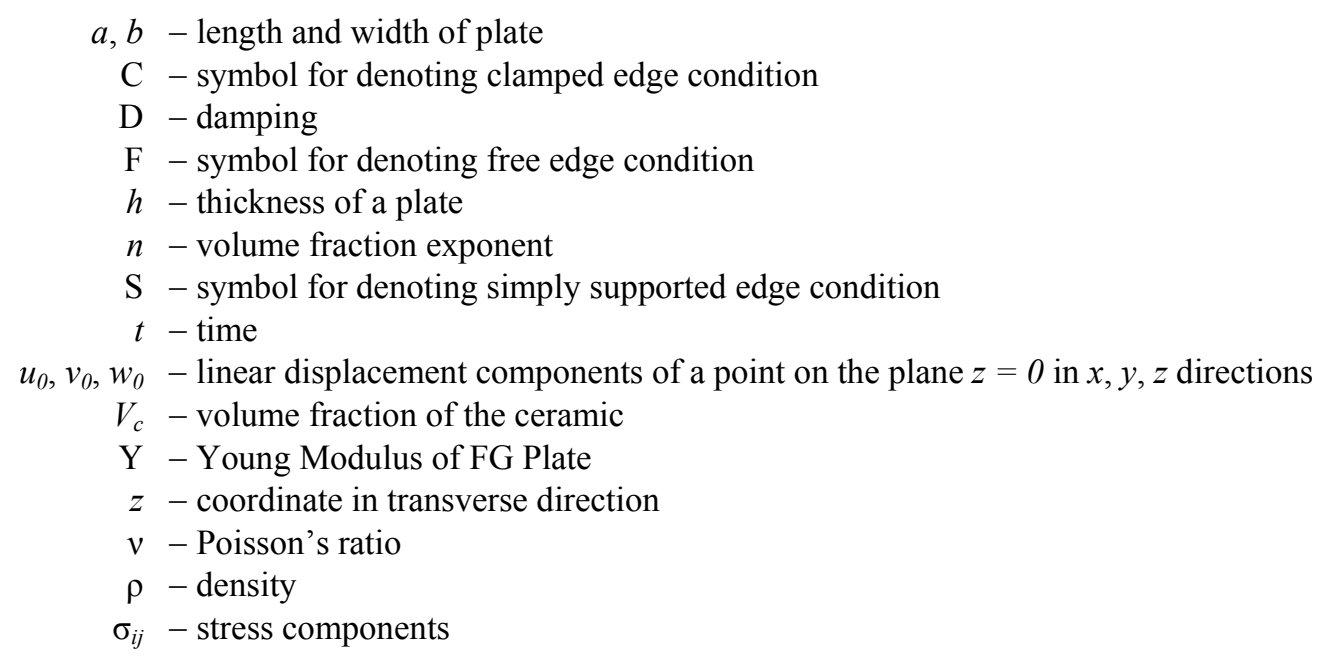

\section{References}

[1] Koizumi M. (1993): The concept of FGM. Ceramic Transactions. - Functionally Gradient Materials, vol.34, pp.310. 
[2] Hirai T. and Chen L. (1999): Recent and prospective development of functionally graded materials in Japan. Materials Science Forum, pp.308-311.

[3] Noda N. (1999): Thermal stresses in functionally graded materials. - Journal of Thermal Stresses, vol.22, pp.477512.

[4] Fuchiyama T. and Noda N. (1995): Analysis of thermal stress in a plate of functionally gradient material. - JSAE Review, vol.16, pp.263-268.

[5] Obata Y. and Noda N. (1994): Steady thermal stresses in a hollow circular cylinder and hollow sphere of a functionally gradient material. - Journal of Thermal Stresses, vol.17, pp.471-487.

[6] Reddy J.N. and Chin C.D. (1998): Thermomechanical analysis of functionally graded cylinders and plates. Journal of Thermal Stresses, vol.21, pp.593-626.

[7] Jimin He and Zhi-Fang Fu (2001): Modal Analysis. - Oxford: Butterworth-Heinemann.

[8] Morales A.L., Rongong J.A. and Sims N.D. (2012): A finite element method for active vibration control of uncertain structures. - Mechanical Systems and Signal Processing, vol.32, pp.79-93.

[9] Xiao-Ming Zhang and Han Ding (2008): Design optimization for dynamic response of vibration mechanical system with uncertain parameters using convex model. - Journal of Sound and Vibration 318, pp.406-415.

[10] Zhao X., Lee Y.Y. and Liew K.M. (2009): Free vibration analysis of functionally graded plates using the elementfree kp-Ritz method. - Journal of Sound and Vibration, vol.319.

[11] Khan I.A. and Awari G.K. (): Harmonic analysis of square plate with and without uncertain parameters. International Journal on Recent and Innovation Trends in Computing and Communication, vol.3, No.2.

[12] Sharma A.K. and Mittal N.D. (2010): Review on stress and vibration analysis of composite plates. - Journal of Applied Sciences, vol.10, No.23, pp.3156-3166.

[13] Sharma A.K., Mittal N.D. and Sharma A. (2011): Free vibration analysis of moderately thick antisymmetric crossply laminated rectangular plates with elastic edge constraints. - International Journal of Mechanical Sciences, vol.53, pp.688-695.

[14] Sharma A.K. and Mittal N.D. (2013): Free vibration analysis of laminated composite plates with elastically restrained edges using FEM. - Central European Journal of Engineering, vol.3, No.2, pp.306-315.

[15] Sharma A.K. and Mittal N.D. (2014): Free vibration analysis of moderately thick Anti-symmetric angleply laminated rectangular plates with elastic edge constraints. - Mechanics of Advanced Materials and Structures, vol.21, pp.341-348.

[16] Asiri Saeed, Hedia Hassan and Eissa Wael (2013): Vibration attenuation using functionally graded material. World Academy of Science, Engineering and Technology, vol.7.

Received: June 30, 2017

Revised: June 22, 2018 